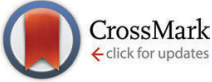

Cite this: Phys. Chem. Chem. Phys., 2017, 19, 7506

Received 3rd January 2017 Accepted 21st February 2017 DOI: $10.1039 / c 7 c p 00037 e$

rsc.li/pccp

\title{
Design of fast ion conducting cathode materials for grid-scale sodium-ion batteries $\dagger$
}

\author{
Lee Loong Wong, Haomin Chen and Stefan Adams*
}

\begin{abstract}
The obvious cost advantage as well as attractive electrochemical properties, including excellent cycling stability and the potential of high rate performance, make sodium-ion batteries prime candidates in the race to technically and commercially enable large-scale electrochemical energy storage. In this work, we apply our bond valence site energy modelling method to further the understanding of rate capabilities of a wide range of potential insertion-type sodium-ion battery cathode materials. We demonstrate how a stretched exponential function permits us to systematically quantify the rate performance, which in turn reveals guidelines for the design of novel sodium-ion battery chemistries suitable for high power, grid-scale applications. Starting from a diffusion relaxation model, we establish a semi-quantitative prediction of the rate-performance of half-cells from the structure of the cathode material that factors in dimensionality of $\mathrm{Na}^{+}$ion migration pathways, the height of the migration barriers and the crystallite size of the active material. With the help of selected examples, we also illustrate the respective roles of unoccupied low energy sites within the pathway and temperature towards the overall rate capability of insertion-type cathode materials.
\end{abstract}

\section{Introduction}

\subsection{Background and motivation}

Novel large-scale electrochemical energy storage systems with revolutionary energy density and power performance are needed to manage power grids based on intermittent renewable sources and to put urban mobility on a sustainable basis. Among the targets for large-scale electrochemical energy storage systems:

- high energy density

- high rate performance

- high energy efficiency (i.e. low overpotential)

- long cycle (and shelf) life

- high safety, reliability and abuse tolerance

- low cost

the low cost and earth abundance of sodium is commonly cited as the key motivation for a transition from $\mathrm{Li}$ - to Na-based cell chemistry, especially in the context of large scale energy storage systems. Still a large fraction of this renewed exploration of sodium-based batteries just mimics approaches that proved successful in Li-ion battery (LIB) technology. Relying on sodium analogues of the conventional layered transition metal oxide cathode materials is, however, problematic as far as it concerns cathode materials containing relatively high cost transition metals such as Co, both as it defies the purpose of cost

Department of Materials Science and Engineering, National University of Singapore, Singapore 117575. E-mail: mseasn@nus.edu.sg

$\dagger$ Electronic supplementary information (ESI) available. See DOI: 10.1039/c7cp00037e reduction and as it overlooks inherent differences in reaction mechanisms of sodium analogues of the classical layered lithium transition metal oxides. In this work, we discuss a more suitable approach in designing Na-ion battery (NIB) materials and NIB systems taking advantage of peculiar properties of sodium and we derive a method to predict the rate performance of insertion cathode materials directly from the crystal structure.

\subsection{External design constraints for sodium-ion battery materials}

The cost advantage of $\mathrm{Na}$ will only translate into commercially viable large-scale NIBs, if the concept of earth-abundance is consistently applied throughout the system design. From the abundance of elements in the Earth's upper crust seen in Fig. 1 the design of NIB electrode materials should concentrate on the most abundant transition metals Fe, Ti and Mn. Lower priority should be given to the less abundant first row transition metals $\mathrm{V}, \mathrm{Cr}$ or the most abundant second row transition metal $\mathrm{Zr}$. Fig. 1 particularly emphasizes that relying on Co oxides will not be sustainable and a transition to $\mathrm{Ni}$ or $\mathrm{Cu}$ offers only a marginal advantage. On the other hand, Earth abundance is only one condition for a low-cost material, and even if this is met, a scalable low cost processing technology is needed to realize the low-cost potential.

In short, rather than copying what worked for LIBs, a rational design of NIB materials has to focus on peculiarities of Na compounds. Based on the strong potential for fast ion mobility, the requirement to limit volume changes during 


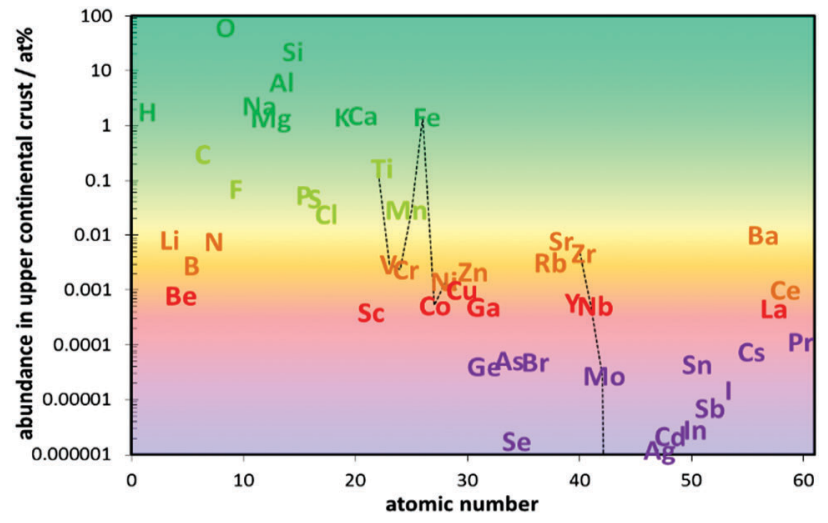

Fig. 1 Atom fraction of the lighter chemical elements in Earth's upper continental crust vs. atomic number (data averaged from two compilations in ref. 1). Transition metal elements are connected by a broken line as a guide to the eye. The abundant elements shown in green should be in the focus of a sustainable materials design, while less common elements shown in red and violet should be avoided in designing NIB materials and the availability of elements of average abundance (shown in orange) may become a limiting factor for low cost large-scale applications.

cycling, stability and energy density considerations we expect that insertion into open framework polyanionic oxides, oxyfluorides or oxynitrides containing abundant transition metals yields the most promising class of NIB electrode materials.

Here, we will thus analyse for a range of such polyanionic NIB cathode materials how suitable the respective structure type is for fast $\mathrm{Na}^{+}$mobility and hence for high rate performance insertion-type NIBs. It will be shown that a stretched exponential function description yields a rational quantitative measure of rate capabilities for insertion-type cathode materials and allows to rationally quantify the relative influence of migration barrier height, pathway dimensionality, the fraction of unoccupied low energy sites in the pathways as well as particle size and operation temperature on the achievable rate performance.

\subsection{SWOT analysis of Na cathode materials and NIB system design}

Considering strengths and weaknesses of $\mathrm{Na}$ compounds for applications in NIBs in comparison to LIB materials, the somewhat lower cell voltage of NIBs slightly affects the achievable energy densities, but will also tend to enhance both cycle and shelf life of NIBs (as well as to a minor extent battery safety) as it moderates the requirements for the electrochemical window of the electrolyte. On the other hand, the larger size of $\mathrm{Na}^{+}$tends to increase the volume changes on cycling insertion compounds. This is inevitable for layered transition metal oxides where sodiation/desodiation corresponds to adding or removing entire sodium layers in the crystal structure (and can only be mitigated by restricting the battery capacity to a partial utilisation of the available $\mathrm{Na}$ ). Moreover, the rate-capability of layered NIB cathode materials is often seriously hampered by $\mathrm{Na}^{+}$ordering as the intra-layer $\mathrm{Na}^{+}-\mathrm{Na}^{+}$distance becomes a crucial structurecontrolling factor. ${ }^{2}$ In polyanion framework compounds, where $\mathrm{Na}^{+}$ions may be more evenly distributed over the unit cell volume, both effects will be much less of a concern, as the sodiation corresponds to filling otherwise vacant channels in a persisting three-dimensional framework that defines the cell volume within rather narrow boundaries. Moreover, the higher contribution of host guest interactions together with weaker $\mathrm{Na}^{+}-\mathrm{Na}^{+}$interactions reduces the hazard of immobilising $\mathrm{Na}^{+}$ ordering. Thus, it appears straightforward to concentrate the search for NIB electrode materials on insertion type compounds, especially if a long cycle life is a key design target besides a high rate performance.

The higher atomic weight of sodium in combination with the above-mentioned slightly higher anode potential obviously imply that NIBs cannot exceed LIBs in terms of gravimetric energy density but can only come close to these. It is, however, often overlooked that NIBs have a strong potential to outshine LIBs in terms of rate performance: the higher atomic number and larger size of $\mathrm{Na}^{+}$ions also mean that $\mathrm{Na}^{+}$are more polarizable and less polarizing than $\mathrm{Li}^{+}$. In addition, the motion of the heavier $\mathrm{Na}^{+}$is less coupled to vibrations in the immobile oxide substructure and hence less harmonic than for $\mathrm{Li}^{+}$. In total this means that, despite the requirement of larger size bottlenecks for ionic motion, alkali ion motion through complex oxides is typically faster in Na compounds than in Li analogues. Provided that the charge carrier mobility within the electrode material controls the overall rate performance of the system, this mobility advantage should directly translate into opportunities for applications requiring high rate performance. It is generally assumed that for batteries relying on insertion electrode materials the charge carrier mobility inside the electrode material is indeed the rate limiting factor (see e.g. ref. 3 and Scheme 1).

The mobility of electrons in mixed-conducting electrode materials is often intrinsically higher and, if not, can be enhanced by conductive additives such as carbon coating. Therefore, the mobility of the inserted (or removed) cations typically controls the rate performance and thus the potential of a phase as a high rate performance electrode material. As suggested by Kalantarian et al. ${ }^{4}$ an exception might be extremely nanosized materials with poor electronic conductivity, for which they qualitatively suggest from DFT calculations that cathodes will show high rate performance if the discharged structure acts as p-type and the charged one as n-type semiconductor, while for the reverse case only lower current rates should be sustained.

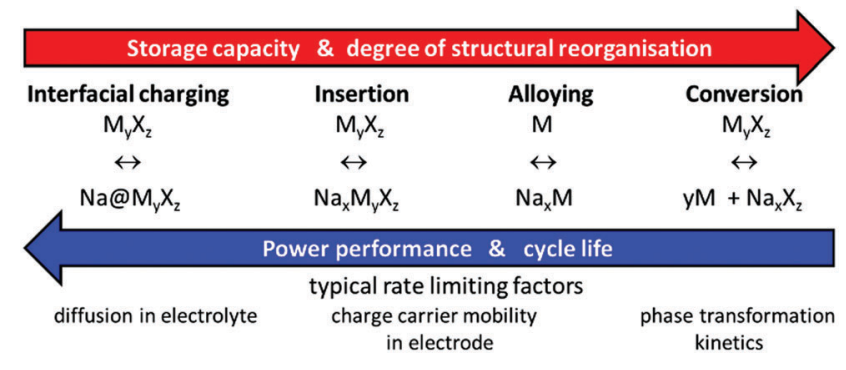

Scheme 1 Interrelation of reversible energy storage mechanisms in $\mathrm{Na}$-based batteries with system performance and rate limiting processes. 
In this work, we discuss the rate performance assuming that it is limited by ion mobility in the cathode material, which will be the default case in Na or Li-based batteries using metal anodes as well as in most practical $\mathrm{Li}$ - and $\mathrm{Na}$-ion batteries. The resulting findings will remain applicable for cases, where the rate limiting process concerns an insertion-type anode.

\subsection{Historical measures of rate performance}

A few decades after the introduction of lead acid batteries Peukert ${ }^{5}$ suggested a simple power law

$$
t=\left(\frac{I_{1}}{I}\right)^{k} t_{1}
$$

to approximately characterize the dependence of the discharge time $t$ of a lead acid battery on the drawn current, $I$, using the discharge time $t_{1}$ at a current of $I_{1}=1 \mathrm{~A}$ as a reference point. The deviation of the Peukert exponent $k \geq 1$ from the ideal value $k=1$ (i.e. from a current-independent capacity) then served as a measure for the rate capability of the battery. Eqn (1) can be rearranged to yield the dependence of the relative capacity $Q$ on the discharge current $I$

$$
\frac{Q(I)}{Q_{1}(I=1 \mathrm{~A})}=\frac{I}{I_{1}} \frac{t}{t_{1}}=\left(\frac{I_{1}}{I}\right)^{k-1}
$$

It is immediately obvious that eqn (2) can only be applied over a limited range of currents $I>I_{1}$ as the relationship would yield a nonsensical increase of the capacity to infinity when applied to arbitrarily small currents. Despite its obvious shortcomings, Peukert's law is still widely used in technical literature both for lead acid batteries (often using different reference currents) and even for a wide range of other battery chemistries though it is commonly known that it does not yield a quantitative prediction of their rate performance. ${ }^{6}$ As will be shown below in Section 3.1, Peukert's law is not only imprecise but yields a fundamentally incorrect rate dependence of the capacity for the technologically relevant range of discharge rates of insertion electrode batteries and can only serve as a crude approximation for extremely high or low rates.

Thus attempts to expand or amend the Peukert equation to mitigate deviations ( $c f$. ref. 7) appear questionable and we here aim to introduce a more rational way to quantify the rate performance starting from the insight that the relevant rate-limiting processes are diffusion relaxation processes. The approach is extendable to the less common case that both charge transfer processes at the electrode surface and diffusion rate affect the overall rate performance in different rate domains. While the theory of frequency dependent relaxation processes is well established in the context of diffusion controlled impedance, as well as to explain diffusion effects on NMR or inelastic neutron spectroscopy, (for reviews see e.g. Dieterich et al. ${ }^{8}$ or $\mathrm{Fu}^{9}$ ) to the best of our knowledge the approach seems to have not yet been utilized to systematically derive a rational and quantitative characterization of the C-rate dependence of capacities for intercalation batteries.

\section{Computational methods}

\subsection{Bond-valence site energy method}

Migration pathways for mobile $\mathrm{Na}^{+}$are analysed both from literature crystal structure data and from series of snapshots of molecular dynamics (MD) simulations by our bond valence site energy approach, as discussed elsewhere. ${ }^{10-12}$ In brief, this modelling of pathways for mobile alkali ions A as regions of low bond valence site energy $E_{\mathrm{BVSE}}(\mathrm{A})$ has been demonstrated to be a simple and reliable way of identifying transport pathways in local structure models, ${ }^{12,13}$ provided that the local structure model captures the essential features of the real structure. While bond valences $s_{\mathrm{A}-\mathrm{X}}=\exp \left[\left(R_{0, \mathrm{~A}-\mathrm{X}}-R_{\mathrm{A}-\mathrm{X}}\right) / b_{\mathrm{A}-\mathrm{X}}\right]$ and hence the bond valence sum mismatch $|\Delta V|$ are often expressed in arbitrary "valence units", they can, as elaborated by our group, ${ }^{14-16}$ be linked to an absolute energy scale by expressing the bond valence as a Morse-type interaction energy between cation $\mathrm{Na}^{+}$and anion $\mathrm{X}$.

$E_{\mathrm{BVSE}}(\mathrm{Na})=\sum_{x} D_{0}\left[\sum_{i=1}^{N}\left(\left(\frac{s_{\mathrm{Na}-\mathrm{X}}}{s_{\mathrm{min}, \mathrm{Na}-\mathrm{X}}}\right)^{2}-\frac{2 \cdot s_{\mathrm{Na}-\mathrm{X}}}{s_{\mathrm{min}, \mathrm{Na}-\mathrm{X}}}\right)\right]+E_{\text {repulsion }}$

The required bond valence parameters are taken from our $s o f t B V$ database as published in ref. 15. Migration pathways for $\mathrm{Na}^{+}$are analysed as regions of low bond valence site energy $E_{\mathrm{BVSE}}(\mathrm{Na})$ in grids spanning the structure model with a resolution of $c a$. $(0.1 \AA) .{ }^{3}$ Starting from an analysis of local minima and saddle points of $E_{\mathrm{BVSE}}(\mathrm{Na})$, the grid analysis utilizes a modified Dewar, Healy and Stewart (DHS)-type path finding algorithm to identify low energy paths connecting the local site energy minima. ${ }^{17}$

For the purpose of analysing $E_{\mathrm{BVSE}}(\mathrm{Na})$ landscapes, Coulomb repulsions are considered only between mobile and immobile cations. Coulomb attraction terms are generally integrated into the Morse attraction term. The charge screening is based on an error function complement term

$$
E_{\text {repulsion }}(\mathrm{A}-\mathrm{B})=\frac{q_{\mathrm{A}} q_{\mathrm{B}}}{R_{\mathrm{A}-\mathrm{B}}} \cdot \operatorname{erf} c\left(\frac{R_{\mathrm{A}-\mathrm{B}}}{f \cdot\left(r_{\mathrm{A}}+r_{\mathrm{B}}\right)}\right)
$$

where $r_{\mathrm{A}}, r_{\mathrm{B}}$ are the covalent radii of the respective cation (or anion) pair A, B and $f$ is a factor (typically of the order $f \approx 0.75$ ) that is empirically linked to the electronegativity distribution in the respective crystal structure. ${ }^{18}$ In practice our software tool varies $f$ for each compound before calculating the pathways to achieve ambient pressure when using the softBV forcefield. Due to the favourable convergence of the chosen interaction models a relatively short cut-off radius of $10 \AA$ can be used enhancing computational efficiency. Both the Morse-type interactions and the Coulomb-repulsion terms are force-shifted to ensure zero energy gradients at the cut-off distance. It may be noted that the same force-field parameters can also be used to conduct MD simulations of the materials, though this requires that Coulomb repulsions between all cation-cation and anionanion pairs are considered. As an example, MD simulations of $\mathrm{Na}_{108} \mathrm{Fe}_{90}\left(\mathrm{SO}_{4}\right)_{144}$ have been conducted with the software GULP $^{19}$ as implemented in Materials Studio $6.0 .^{20}$ Details of 
the simulation method and results for this compound can be found in our recent separate publication. ${ }^{21}$

\section{Results}

\subsection{Fitting of experimental rate capability data}

As a basis for our study we gathered rate performance data for about 25 NIB cathode materials from the recent literature ${ }^{22-47}$ focusing on room temperature data for composite electrode systems, where the mobility of electronic charge carriers should be high enough to be not rate limiting (either due to an intrinsically high electronic conductivity of the active cathode material or by carbon coating). Data for carbon-coated materials are therefore preferably adopted in this compilation.

At this stage, we also avoided materials with median particle sizes below $40 \mathrm{~nm}$ to ensure that the rate performance at high C-rate is primarily limited by bulk ionic transport. Fig. 2 shows a compilation of the relative capacity for some of the polyaniontype $\mathrm{Na}^{+}$ion insertion cathode materials used in this study $v s$. the logarithm of the rate of discharge. Here the relative capacity $Q_{\text {rel }}(C)$ is defined as the actual specific capacity $Q$ of a cathode material at a given C-rate divided by its theoretical specific capacity $Q_{\text {theoretical }}$. We found in general similar trend in all the rate performances data - most compounds show considerable relative capacity at low C-rate, but eventually exhibit rapid fading where relative capacity drops to about $1 / 3$ for every order of magnitude increase in C-rate. A qualitative approach might thus, as shown in Fig. 2, categorize the materials into the order of magnitude of the C-rate, where the rapid capacity fading sets in.

Peukert's law is - as mentioned above - found to be fundamentally unsuitable for a quantitative modelling of diffusion limited rate performance. In the plot of $Q_{\text {rel }} v s$. logarithm of the C-rate of Fig. 2 any power law such as Peukert's law will invariably suggest a convex function, while experimental data

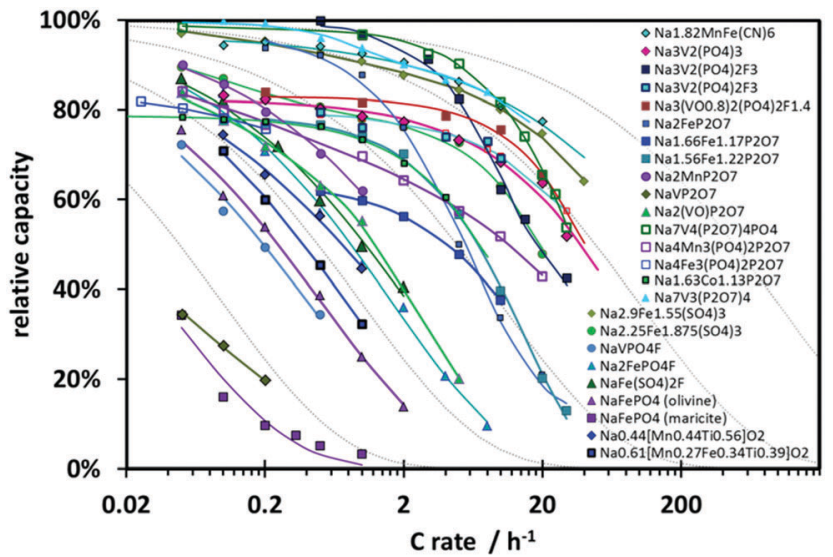

Fig. 2 Rate performance data of various polyanionic compounds recently reported in literature. All compounds eventually show rapid capacity fading at higher $\mathrm{C}$-rates. Different categories are formed based on the C-rate at which rapid capacity fading is observed. Dotted lines correspond to the rate capability of materials predicted according to eqn (5a) assuming parameter values $\alpha=0, \beta=0.5$ for all dotted lines, but varying values of $W=0.1,1,10,100$, or $1000 \mathrm{~h}^{-1}$. consistently suggest a concave or sigmoidal shape of the $Q_{\text {rel }}(C)$ relationship. Thus $Q_{\text {rel }}(C)$ cannot be fitted meaningfully by eqn (2). For all the displayed systems, it is however possible to fit the variation of $Q_{\mathrm{rel}}(C)$ with reasonable precision when assuming a stretched exponential relationship

$$
Q_{\text {rel }}(C)=\frac{Q(C)}{Q_{\text {theoretical }}}=(1-\alpha) \cdot \exp \left[-\left(\frac{C}{W}\right)^{\beta}\right]
$$

with a stretching exponent $\beta$ typically in the range $0.5 \leq \beta \leq 1$ and a "relaxation frequency" $W$ that assumes values of the order 0.04 to $200 \mathrm{~h}^{-1}$. Since the C-rate $C$ for galvanostatic discharge conditions corresponds to the inverse of the discharge time $t$ the correlation may alternatively be expressed as eqn (5b):

$$
Q_{\text {rel }}\left(\frac{1}{t}\right)=\frac{Q(C)}{Q_{\text {theoretical }}}=(1-\alpha) \cdot \exp \left[-\left(\frac{w}{t}\right)^{\beta}\right]
$$

The three parameters of this empirical relationship have clearly distinct physical meanings. The parameter $\alpha$ formally indicates the fraction of the theoretical capacity that remains inaccessible even at infinitely low C-rates, due to the consumption of mobile ions to form a SEI layer, due to an inadequate choice of the voltage window, etc. Practically, it will also include a capacity loss due to slow processes (at the electrode-electrolyte interface) for which the relaxation rate is below the studied C-rate "frequency" window.

The characteristic relaxation frequency $W$ in eqn (5a) (or relaxation time $w=1 / W$ in eqn (5b)) defines the point of inflection of the stretched exponential function, i.e. for a C-rate $C=W$ the relative capacity dropped to $1 / e \approx 37 \%$ of its value at infinitely low discharge rate. Therefore, it may be convenient to use for $W$ the unit $\mathrm{h}^{-1}$ that is commonly used to specify the $\mathrm{C}$ rate. The stretching exponent $\beta$ defines the slope

$$
\frac{\mathrm{d} Q_{\text {rel }}}{\mathrm{d} \ln (C)}=\frac{\mathrm{d} Q_{\text {rel }}}{\mathrm{d} \ln \left(\frac{1}{t}\right)}=-\frac{(1-a)}{e} \beta
$$

in the "nearly constant loss" region around the point of inflection. To facilitate a formal comparison with Peukert's law eqn (5b) may also be rewritten using a linear approximation as

$$
\frac{Q_{\mathrm{rel}}}{(1-a)}=\frac{I}{I_{0}} \frac{t}{t_{0}} \approx\left(\frac{t^{\beta}}{t^{\beta}+w^{\beta}}\right),
$$

where the reference state $\left(I_{0}, t_{0}\right)$ now corresponds to an infinitely small discharge current. Thus, only for high C-rates where $t \ll w$ the rate dependences formally assume analogous functional forms with

$$
\left(\frac{t}{t_{1}}\right)^{\frac{k-1}{k}} \propto\left(\frac{t}{w}\right)^{\beta}
$$

In reality, the Peukert law is however applied for relatively low rates, where the charge transfer kinetics at the electrodeelectrolyte interface controls the reaction rate and overpotential, and this is often as much a question of system design as it is of electrode materials selection. Thus, despite such a formal analogy it should not be expected that the conventional values 
of $k(1<k<1.5$ describing the influence of activation overpotential effects on rate capability) can be related to the exponent $\beta$ that characterises the effect of mass transport processes inside the electrode material on the rate capability. The formal analogy may in principle be utilized vice versa to set up a generalised version of eqn (5a) that describes the rate capability over a wider range of C-rates under the influence of both activation and concentration polarisation by

$Q_{\text {rel }}(C)=\alpha \cdot \exp \left[-\left(\frac{C}{W_{\text {act }}}\right)^{\beta_{\text {act }}}\right]+(1-\alpha) \cdot \exp \left[-\left(\frac{C}{W}\right)^{\beta}\right]$

It may be noted that parameter $\alpha$ in eqn (9) now refers to the fraction of the capacity that is lost when the C-rate significantly exceeds the relaxation frequency $W_{\text {act }}$ of the charge transfer process at the electrode surface. In contrast to the Peukert equation this functional form ensures that $0 \leq Q_{\text {rel }}(C) \leq 1$ for any C-rate. Peukert exponents in the range $1<k<1.5$ translate into $0 \leq \beta_{\text {act }} \leq 1 / 3$ and $W_{\text {act }}$ will typically be orders of magnitude smaller than $W$. For most experimental capacity data sets $\mathrm{C}$ rates of the order of $W_{\text {act }}$ will be below the range of studied $\mathrm{C}$ rates $\left(C \gg W_{\text {act }}\right)$ and experimental data can be fitted according to eqn (5a), i.e. assuming that concentration polarisation is the only relevant relaxation process.

\subsection{Theory of rate performance of insertion electrode materials}

The observed stretched exponential, i.e. Kohlrausch-WilliamsWatts-like, ${ }^{48,49}$ relationship of eqn (5a) between relative capacity $Q_{\text {rel }}$ and C-rate may be understood as the consequence of two (or more) competing relaxation processes. To illustrate this, let us first consider a one-dimensional (1D) diffusional process assuming two independent relaxation mechanisms for the local relaxation of an ion at a site: the first process is a diffusion-independent relaxation involving the relaxation frequency $C_{1}$ assumed for the sake of simplicity to be the same for all sites; the other involves an instantaneous relaxation triggered by the arrival of a second ion forming an interstitialcy pair. Therefore, the response function describing the polarisation decay after the sudden removal of a steady electric field can be written as the product of two terms: ${ }^{50-52}$

$$
Q_{\text {rel }}(C)=\exp \left[-\left(\frac{C}{C_{1}}\right)\right][1-P(C)]
$$

where $P(C)$ is the probability that a triggering ion has reached the site within the period $1 / C$, and consequently $[1-P(C)]$ is the probability that such an ion does not arrive within that period. It may be noted in passing that all the relationships were originally derived in time space and are translated here to frequency space to facilitate the comparison with eqn (5a). Bordewijk $^{51}$ expanded the $1 \mathrm{D}$ diffusion-controlled relaxation model to include all relaxation-triggering species and not just nearest neighbours. In the limit of a large number of triggering entities he finds

$$
[1-P(C)]=\exp \left[-\left(\frac{C}{C_{2}}\right)^{0.5}\right]
$$

in the case of diffusion-triggered relaxation in one dimension, where $C_{2}$ is proportional to the diffusion constant $D$ of the (triggering) ion so that in total the correlation function for $1 \mathrm{D}$ diffusion becomes

$$
q(c)=\exp \left[-\left(\frac{C}{C_{1}}\right)\right] \exp \left[-\left(\frac{C}{C_{2}}\right)^{0.5}\right] \approx \exp \left[-\left(\frac{C}{C_{\text {eff }}}\right)^{\beta}\right]
$$

and the effective stretching exponent $\beta$ varying from 0.5 (for $C_{1} \gg C_{2}$ ) to 1 (for $C_{2} \gg C_{1}$ ). Bordewijk ${ }^{51}$ also showed (again in time rather than frequency space) that the same functional form results for three-dimensional diffusion. To this end, he assumed that the relaxation is initiated when a defect enters a spherical region around the central position. In that case both $C_{1}$ and $C_{2}$ will linearly depend on the diffusion coefficient (assuming that the diffusion-less relaxation process does no longer play a role for the $3 \mathrm{D}$ case) and $C_{2} / C_{1}$ will be a function of the defect concentration, but will be independent of the diffusion coefficient suggesting a transition from $\beta=0.5$ to 1 as the defect concentration increases. Later extensions of the model show that formally analogous expressions also apply for intermediate incl. fractal dimensions. ${ }^{53}$ Thus, it should be kept in mind that the same functional form will result irrespective of the local dimensionality of the ion migration pathways.

It may be noted that such a transition from non-Debye to Debye-type relaxation is consistently found from a variety of models for dielectric relaxations in complex disordered systems (which mostly have been originally elaborated to further a deeper understanding of ion conduction in glasses) such as Ngai's coupling concept, ${ }^{54}$ where $C_{1}$ and $C_{2}$ may be thought of as resulting from the independent short range and correlated long-range motion of ions, respectively, or Funke's jump relaxation model, ${ }^{55}$ where the competing relaxation rates correspond to the relaxation of the mismatch in charge distribution due to an initially successful hop via either a correlated backwards hop or by the rearrangement of the neighbouring ions. The latter concept appears particularly suited for a straightforward application to the complex pathways identified below in Section 3.3 of this paper.

\section{3. $\mathrm{Na}^{+}$migration pathways for $\mathrm{Na}$-ion cathode materials}

In this section, we will analyse both the $\mathrm{C}$ rate dependence of the discharge capacity and the pathways for $\mathrm{Na}^{+}$ion migration pathways through the structures of a wide range of potential NIB cathode materials and discuss relationships between both ways of characterising the rate capability of the materials.

3.3.1. Cathodes with one-dimensional $\mathrm{Na}^{+}$migration channels. Low-dimensional pathways for ion migration are commonly known to be bottlenecks for fast ionic conductivity and according to the model developed in Section 3.2 will have only limited rate-capability. Thus we start our survey on cathode materials made of earthabundant elements with three classes of NIB cathode materials that based on the reported crystal structures should exhibit strictly onedimensional pathways: alluaudite-type " $\mathrm{Na}_{2} \mathrm{Fe}_{2}\left(\mathrm{SO}_{4}\right)_{3}$ ", ${ }^{22,25}$ olivinetype $\mathrm{NaFePO}_{4}{ }^{38}$ and the $\mathrm{Na}_{0.44} \mathrm{MnO}_{2}$ structure type ${ }^{43,44,56,57}$ in order to understand why their reported rate performances differ substantially, as shown in Fig. 2 (and Fig. S1 in the ESI $\dagger$ ). 

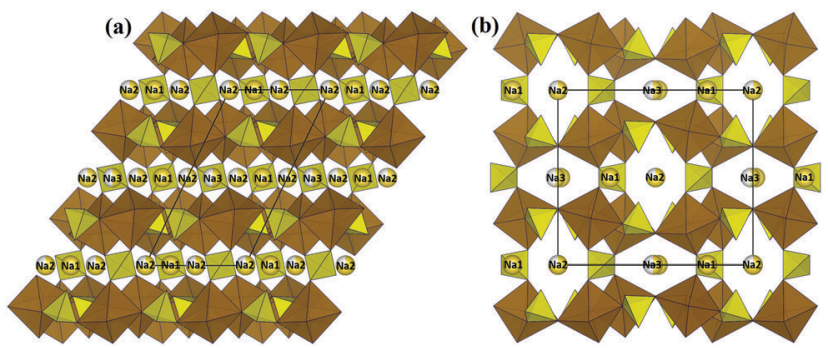

Fig. 3 Structure of $\mathrm{Na}_{2+x} \mathrm{Fe}_{2-x / 2}\left(\mathrm{SO}_{4}\right)_{3}$ (SG: C2/c) projected along (a) the $b$ axis and (b) the $c$ axis. Sodium ions are shown as yellow spheres and the types are marked accordingly. $\mathrm{SO}_{4}$ and $\mathrm{FeO}_{6}$ groups are represented by yellow tetrahedra and brown octahedra respectively. Black lines correspond to the unit cell.

It may be noted in passing that the $Q(C)$ curve shown for $\mathrm{Na}_{2.25} \mathrm{Fe}_{1.875}\left(\mathrm{SO}_{4}\right)_{3}$ is one of the examples where a second relaxation process seems to be observable at a low C-rate (which can be nearly perfectly fitted by eqn (9) with the two relaxation frequencies $W \approx 40 \mathrm{~h}^{-1}$ and $\left.W_{\text {act }}=0.09 \mathrm{~h}^{-1}\right)$.

Alluaudite-type " $\mathrm{Na}_{2} \mathrm{Fe}_{2}\left(\mathrm{SO}_{4}\right)_{3}$ " originally caught our attention due to its combination of low cost, high voltage and in fact decent rate performance. ${ }^{22}$ As compared to their phosphate counterparts which typically show $c a .3 \mathrm{~V}$ for $\mathrm{Fe}^{3+} / \mathrm{Fe}^{2+}$ redox couple, the more electronegative $\mathrm{SO}_{4}{ }^{2-}$ units in this compound lead to a high Fe redox potential of $3.8 \mathrm{~V}$ ( $v s$. Na) and an initial reversible capacity of $102 \mathrm{~mA} \mathrm{~h} \mathrm{~g}{ }^{-1} \cdot{ }^{22}$ In the alluaudite structure edge-sharing bi-octahedral $\mathrm{Fe}_{2} \mathrm{O}_{10}$ are interconnected via corner-sharing $\mathrm{SO}_{4}$ tetrahedra to form a three-dimensional framework with open tunnels ( $c f$. Fig. 3). These tunnels are occupied by three distinct types of $\mathrm{Na}^{+}$ions (fully occupied $\mathrm{Na}(1)$ site and partially occupied $\mathrm{Na}(2), \mathrm{Na}(3)$ sites).

In their original work, Barpanda et $a .^{22}$ noticed Fe deficiency while synthesizing " $\mathrm{Na}_{2} \mathrm{Fe}_{2}\left(\mathrm{SO}_{4}\right)_{3}$ " by low-temperature solid-state reactions (and hence the formation of $\mathrm{FeSO}_{4}$ as an impurity phase). We consider this to be an inherent feature of the material under the chosen synthesis conditions and modelled it more generally as $\mathrm{Na}_{2+x} \mathrm{Fe}_{2-x / 2}\left(\mathrm{SO}_{4}\right)_{3}$ with a representative local structure model. ${ }^{21}$ The validity of this assumption was later corroborated by Oyama et al. ${ }^{58}$

Sodium ion migration pathways in " $\mathrm{Na}_{2} \mathrm{Fe}_{2}\left(\mathrm{SO}_{4}\right)_{3}$ " based on our BVSE method are shown in Fig. $4 \mathrm{a}$ and b. Long-range $\mathrm{Na}^{+}$transport will be primarily one-dimensional along the $c$ direction involving two distinct 1D paths. One path follows the $\mathrm{Na}(3)-\mathrm{Na}(3)$ channel with a low migration barrier of $0.25 \mathrm{eV}$ alongside desirable vacancies (50\%). Fully occupied $\mathrm{Na}(1)$ sites are connected to this path and contributes additional mobile $\mathrm{Na}^{+}$. Another path involves $\mathrm{Na}(2)$ (site occupancy 0.75 ) also along the $c$ direction with an activation energy of $0.48 \mathrm{eV}$. In general, there is a good agreement with the literature $a b$ initio study. ${ }^{22}$ Quantitatively, the slight differences in migration barriers should partly be attributed to the different sodium content, as the DFT analysis and our BVSE modelling involves fully desodiated and sodiated structures, respectively. Indeed, in the BVSE analysis seen in Fig. 4c, fully occupied $\mathrm{Na}(1)$ sites, as to be expected, correspond to the lowest energy sites, while a $c a .0 .2 \mathrm{eV}$ higher site energy is found for the partially occupied $\mathrm{Na}(2)$ sites. In the hypothetical structure, $\mathrm{Na}_{0.125} \mathrm{Fe}_{2}\left(\mathrm{SO}_{4}\right)_{3}$, from the DFT analysis, the $\mathrm{Na}(2)$ site becomes energetically more stable than $\mathrm{Na}(1)$ site. The energy barrier related to $\mathrm{Na}(3)-\mathrm{Na}(3)$ hops is hardly affected, although the $\mathrm{Na}(3)$ site energy is significantly increased in the desodiated phase.

Based on the idealised stoichiometric structure model it appeared difficult to reconcile the excellent rate performance of this compound to its migration pathway topology (i.e. purely 1D conduction pathways). Based on previous studies, Fe site deficiency may open up additional pathways cross-linking the fast-ion conducting channels to higher dimensional pathway (a)

(b)

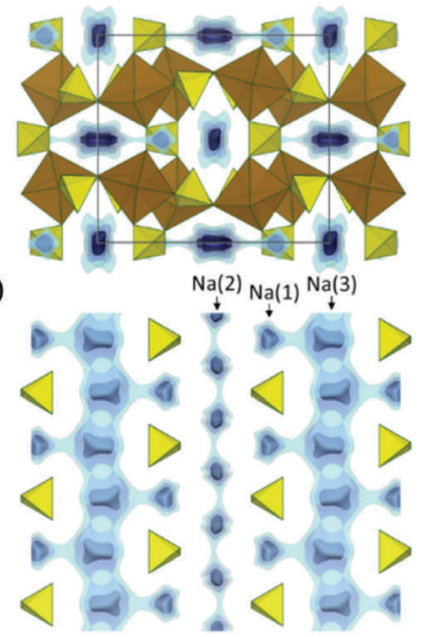

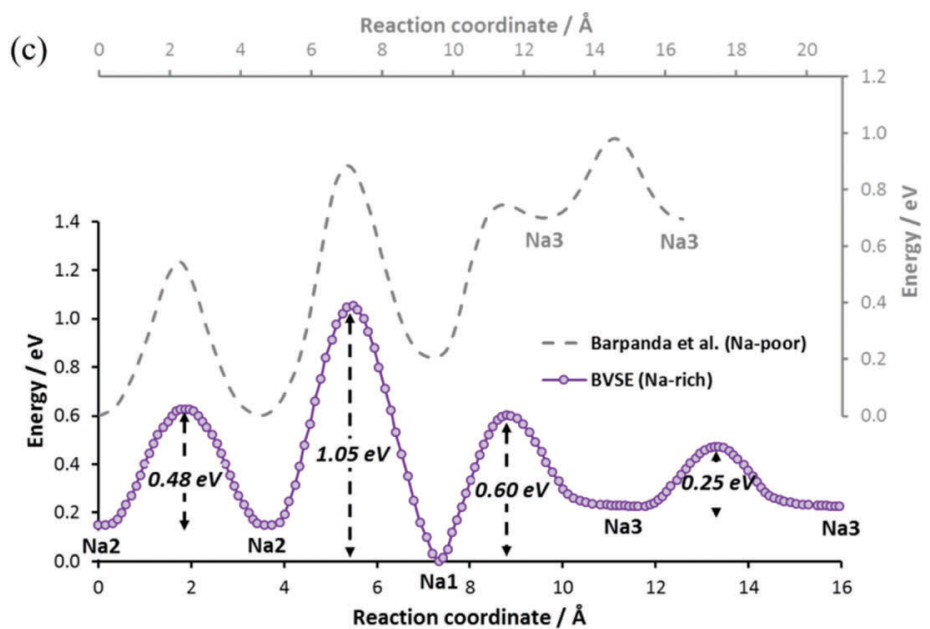

Fig. $4 \mathrm{Na}^{+}$ion migration pathways based on BVSE model represented by blue energy isosurfaces superimposed on a structure model of $\mathrm{Na}_{2} \mathrm{Fe}_{2}\left(\mathrm{SO}_{4}\right)_{3}$ (a) projected along the fast channels $c$ direction and (b) for a slice of the structure with $0.3<x<0.7$ in the $b c$ plane. This slice clearly shows two distinct 1D paths involving all three $\mathrm{Na}^{+}$types. (c) Migration barriers for $\mathrm{Na}^{+}$ion diffusion in $\mathrm{Na}_{2.25} \mathrm{Fe}_{1.875}\left(\mathrm{SO}_{4}\right)_{3}$ based on BVSE model for the experimental crystal structure data from ref. 22. From left to right, the migration barriers correspond to transport long $\mathrm{c}$ axis for $\mathrm{Na}$ (2) channels, the connection between $\mathrm{Na}(2)$ and $\mathrm{Na}(1)$ sites, the local path allowing $\mathrm{Na}(1)$ to serve as additional $\mathrm{Na}^{+}$source, and finally the fast $\mathrm{Na}(3)$ channel. Figure adapted from ref. 21. 
(a)

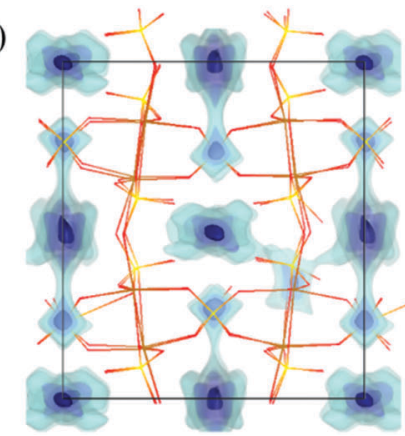

(b)

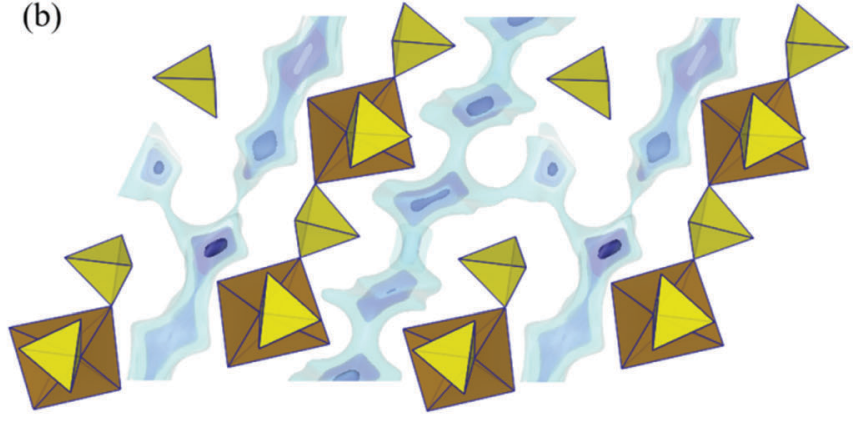

Fig. 5 (a) Isosurfaces of constant BVSE for $\mathrm{Na}^{+}$superimposed on the geometry-optimised local structure model of $\mathrm{Na}_{2.25} \mathrm{Fe}_{1.875}\left(\mathrm{SO}_{4}\right)_{3}$ projected along the $\mathrm{c}$ axis. (b) Details from the graph (a) showing a superposition of $\mathrm{Na}^{+}$migration pathways for different BVSE values projecting the central portion of the unit cell $0.3<y<0.7$ (close to the Fe site vacancy in this local structure model) along the $b$ axis.

networks with moderate activation energy. ${ }^{11,16}$ To explore the role of vacancies at Fe sites, a local structure model was constructed based on a $1 \times 1 \times 2$ superstructure by assigning the sodium sites according to their site occupancies. In particular, 1 out of the 16 Fe sites is vacant (experimentally refined Fe site occupancy $\approx 0.94$ ). The superstructure was subsequently relaxed based on our softBV force-field.

As seen in Fig. 5a and b, our BVSE model reveals the role of vacant $\mathrm{Fe}^{2+}$ sites: they turn into interstitial sites for the $\mathrm{Na}^{+}$which cross-link two adjacent $\mathrm{Na}(2)$ and $\mathrm{Na}(3)$ pathway channels. The resulting migration pathway is now effectively of a higher dimensionality than the original 1D model. Such cross-linking thus provides resilience against blocking defects, in combination with the facile migration along partially occupied 1D channels explains the experimentally observed high rate performance. As we showed in our previous study, BVSE reveals also other valuable insights into such local structure models incorporating Fe vacancies, including the modification of migration profiles along the paths in the vicinity of such defects. ${ }^{21}$ The concentration and distribution of Fe vacancies thus determines the overall rate performance and the practical dimensionality of the pathways. The outstanding rate performance $\left(W=244 \mathrm{~h}^{-1}\right)$ reported recently by Meng et al. ${ }^{25}$ for Fe-depleted non-stoichiometric $\mathrm{Na}_{2.9} \mathrm{Fe}_{1.55}\left(\mathrm{SO}_{4}\right)_{3}$ (i.e. $x=0.9$ ) seems to confirm this interpretation.

The $\mathrm{Na}_{0.44} \mathrm{MnO}_{2}$ structure type for which we mainly use $\mathrm{Na}_{0.61}\left[\mathrm{Mn}_{0.27} \mathrm{Fe}_{0.34} \mathrm{Ti}_{0.39}\right] \mathrm{O}_{2}$ (NMFTO) ${ }^{43}$ as an example, is characterized by the presence of two distinct tunnels ( $c f$. Fig. 6a) for the $\mathrm{Na}^{+}$: part of the $\mathrm{Na}^{+}$are hosted in large, S-shaped tunnels, and the remaining $\mathrm{Na}^{+}$are hosted in smaller tunnels. This is in contrast with the $\mathrm{NaFePO}_{4}$ olivine structure type where all $\mathrm{Na}^{+}$ ion pathways are single channels ( $c f$. Fig. $6 \mathrm{c}$ and d). In $\mathrm{NaFePO}_{4}$ (first prepared by ion exchange from $\left.\mathrm{LiFePO}_{4}\right)^{59}$ the onedimensional pathways are fully isolated from each other and should thus be highly susceptible to blocking by defects.

In NMFTO, BVSE model reveals three crystallographically distinct energy minima ( $c f$. Fig. $6 \mathrm{~b}$ ) in the S-shaped tunnels separated by shallow energy barriers $(<0.2 \mathrm{eV})$, where all three sites are partially occupied by sodium ions (site occupancy factors for Na2: 0.797, Na3: 0.787, Na4: 0.195). Extremely short apparent $\mathrm{Na}^{+}-\mathrm{Na}^{+}$distances (Na2-Na4: $1.49 \AA$ ) within this

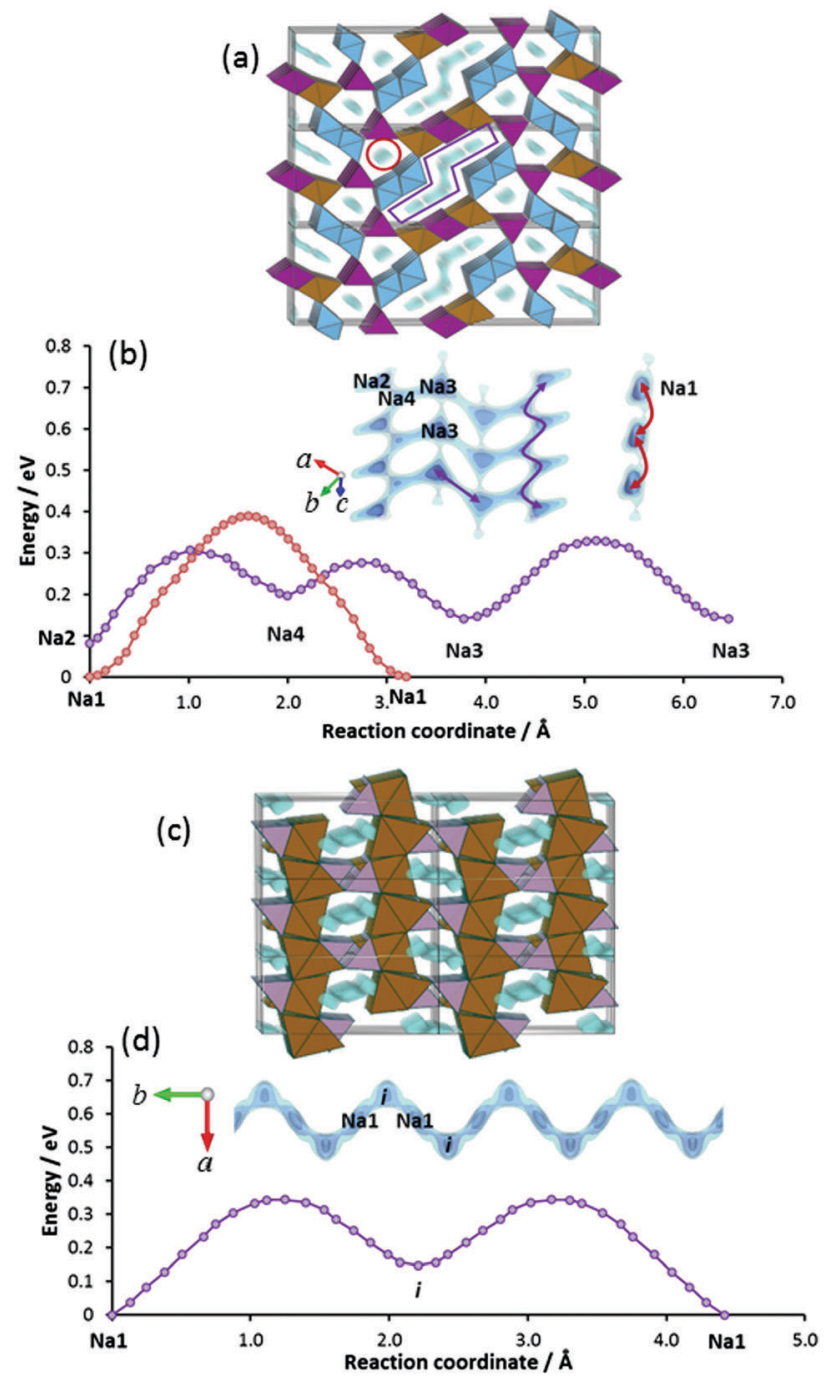

Fig. 6 Crystal structure of (a) $\mathrm{Na}_{0.61}\left[\mathrm{Mn}_{0.27} \mathrm{Fe}_{0.34} \mathrm{Ti}_{0.39}\right] \mathrm{O}_{2}$ and (c) olivine $\mathrm{NaFePO}_{4}$ showing channels along $c$ and $b$ axis, respectively suitable for $\mathrm{Na}^{+}$conduction as represented by blue energy isosurfaces. In the former compound, two types of tunnels exist: large, S-shaped tunnels (highlighted in purple) and small Na1 tunnel (highlighted in red) (b) migration pathways for $\mathrm{Na}_{0.61}\left[\mathrm{Mn}_{0.27} \mathrm{Fe}_{0.34} \mathrm{Ti}_{0.39}\right] \mathrm{O}_{2}$ along the $\mathrm{S}$-shaped tunnel (purple) and $\mathrm{Na1}$ tunnel (red). (d) Migration pathways for olivine $\mathrm{NaFePO}_{4}$ along the $b$ channels involving sodium sites (Na1) and interstitial sites (i). 
pathway are due to the distribution of locally mobile $\mathrm{Na}^{+}$ions over multiple adjacent energy minima.

Such interconnected low-lying energy sites extend in the $c$ axis to form independent 1D tunnels. Within each of these S-shaped tunnels, Na3-Na3 hops enable the formation of a continuous ribbon-like 1D pathway ( $c f$. inset to Fig. 6b) that is expected to be more resilient against blocking by impurity defects than the Na1 channel. This is also in line with the respectable specific capacity observed experimentally at low cycling rate even with micrometresized particles. ${ }^{43}$ The lowest energy sodium site was found to be the Na1 site within the small tunnel, where the presence of vacancies along this Na1 path (ca. 10\% vacancies) distinguishes this compound from other members of the $\mathrm{Na}_{0.44} \mathrm{MnO}_{2}$ family, for which the Na1 sites are fully occupied. Coupled with a moderate migration barrier of $0.39 \mathrm{eV}$, this supports the experimental observation that some $\mathrm{Na}^{+}$ion extraction from these channels might be possible in NMFTO. ${ }^{43}$

The comparison among olivine, alluaudite and $\mathrm{Na}_{0.44} \mathrm{MnO}_{2}$ structure type cathode materials in terms of their rate performances in Fig. S1 (ESI $\dagger$ ) shows that the rate-dependent capacity reduction is characterised by $W=0.5 \mathrm{~h}^{-1}$ in the single channels of olivine-type $\mathrm{NaFePO}_{4}$, by $c a$. $W=0.8-1.5 \mathrm{~h}^{-1}$ for $\mathrm{Na}_{0.44} \mathrm{MnO}_{2}$ related cathode materials with their $1 \mathrm{D}$ pathway ribbons, but reaches $W=40 \mathrm{~h}^{-1}$ or $244 \mathrm{~h}^{-1}$ for the alluaudite-type $\mathrm{Na}_{2+x} \mathrm{Fe}_{2-x / 2}\left(\mathrm{SO}_{4}\right)_{3}$ (NFS) with $x=0.25$ or $x=0.9$ (the latter is also optimized by forming a composite with single-walled carbon nanotubes). It is to be stressed that such significant difference in rate performance between NFS and the other two structure types is largely due to the cross-linking among its 1D channels via Fe vacancies, giving rise to paths of higher effective pathway dimensionality. The tendency for cross-linking of pathways in the other two structure types is much weaker as the formation of a relevant concentration of antisite defects requires a substantial defect formation energy and would involve a reduced mobility in channel direction by the Fe on Na sites.

3.3.2. Two-dimensional $\mathrm{Na}^{+}$migration channel materials with high migration barriers. The obvious vulnerability of materials containing strictly one-dimensional pathways might lead to the impression that compositional analogues with two-dimensional pathways should always have a major advantage. While this is in general also observed experimentally, it should be kept in mind that beyond the pathway topology, the migration barrier within this pathway will control the rate-capability. To weigh the influence of pathway dimensionality against migration energy along the pathway, we will look into a few cathode materials that according to our analysis exhibit two-dimensional (2D) pathways, but with relatively high migration barriers along the paths (for details see Fig. S2 of the ESI $\dagger$ ).

Among these, Eldfellite-type $\mathrm{Na}_{1+x} \mathrm{Fe}\left(\mathrm{SO}_{4}\right)_{2}$ is one of the members of the sulfate-based cathode family and could be seen as compositionally related to the alluaudite-type iron sulfates discussed above. ${ }^{24}$ However, it has a distinct structure consisting of stacked layers of corner-sharing $\mathrm{FeO}_{6}$ and $\mathrm{SO}_{4}$ polyhedra (Fig. 7a), while two energy minima sites exist within the interlayer spaces, namely the fully occupied $\mathrm{Na} 1$ sites $(2 \mathrm{c}$ at $0,0,0.5)$ and interstitial site $(4 \mathrm{i}$ at $0.226,0.5,0.278)$ that are vacant in the desodiated state. Since the two site energies differ only slightly, it might also be possible that sodium redistribution occurs upon sodiation to mitigate the Coulomb repulsion between $\mathrm{Na}$ on the equilibrium and interstitial sites $(\mathrm{Na}-\mathrm{i}$ distance $=2.66 \AA$; $\mathrm{i}-\mathrm{i}$ distance $=4.08 \AA$ ).

In the absence of structural reports for synthetic eldfellite, our pathway analysis is based on the structure data for the volcanic mineral Eldfellite. ${ }^{60}$ We relaxed the structure model computationally using our softBV-based forcefield. In the relaxed structure the occupied Na site becomes the most favourable site, but the energy of the i site is only minutely higher ( $c f$. Fig. 7b). The high migration barrier of $0.93 \mathrm{eV}$ also dictates that ion diffusion kinetics becomes increasingly sluggish as the charged state is approached. It may be noted here that (in the absence of experimental data for the sodiated state) this barrier is determined for the desodiated state, whereas pathways for all other compounds in this paper are studied for the discharged (i.e. sodiated) state and (by analogy to our findings for structure types where both sodiated and desodiated phases could be analysed) a somewhat lower barrier may be expected for the fully sodiated $\mathrm{Na}_{2} \mathrm{Fe}\left(\mathrm{SO}_{4}\right)_{2}$.

Details for further cathode materials featuring two-dimensional Na-ion migration paths including tavorite-type $\mathrm{Na}_{2} \mathrm{FePO}_{4} \mathrm{~F}$ and maricite-type $\mathrm{NaFePO}_{4}$ are shown in the ESI $\dagger$ ( $c f$. Fig. S3). In brief, the enhancement in rate performance (from $W=0.04 \mathrm{~h}^{-1}$ in maricite $\mathrm{NaFePO}_{4}$ to $W=1.67 \mathrm{~h}^{-1}$ in $\mathrm{Na}_{2} \mathrm{FePO}_{4} \mathrm{~F}$ ) can be related
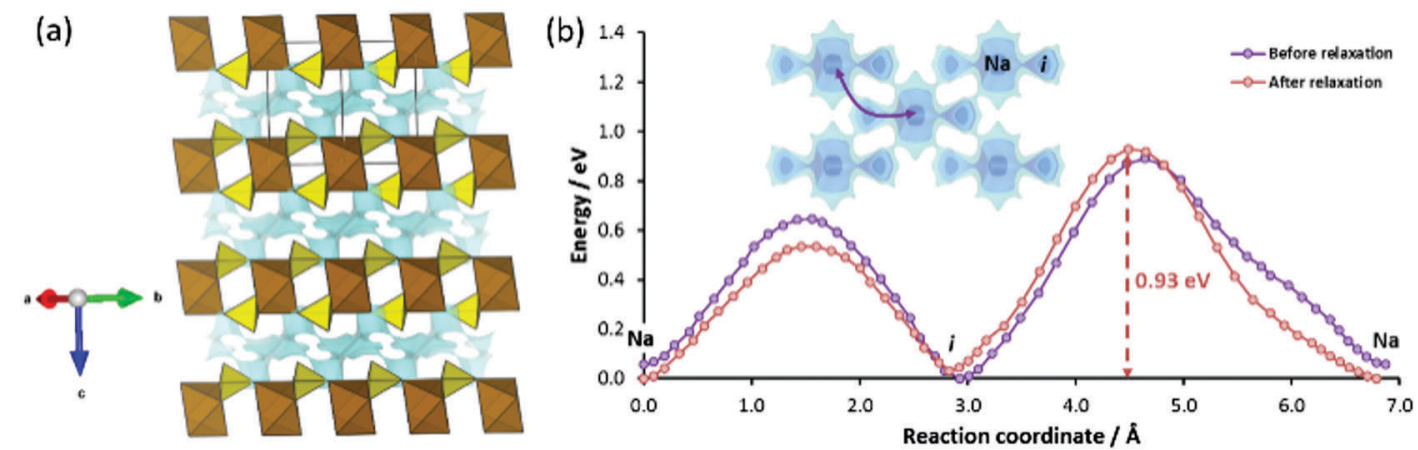

Fig. 7 (a) Eldfellite structure of $\mathrm{NaFe}\left(\mathrm{SO}_{4}\right)_{2}$ with layered $\mathrm{Na}^{+}$conduction pathways being shown as cyan energy isosurface (b) reaction pathway involved for long-range $2 \mathrm{D} \mathrm{Na}^{+}$transport. Two symmetrically distinct energy sites were found, $\mathrm{Na}$ site and interstitial site. 
to the lower migration barrier $(1.4 \mathrm{eV} v s$. $0.58 \mathrm{eV})$. The overall kinetics in $\mathrm{Na}_{2} \mathrm{FePO}_{4} \mathrm{~F}$ is still expected to be relatively slow due to the moderately high migration barrier of $0.58 \mathrm{eV}$ in combination with a lack of vacancies for sodium. Thus, a 2D transport network topology does not necessarily translate into high rate capability. In the next section, we demonstrate how high rate performance can be unlocked by lower migration barriers $(<0.5 \mathrm{eV})$ while maintaining an at least 2-dimensional pathway network.

3.3.3. Pyrophosphates and related compounds. Transition metal pyrophosphates $\left(\mathrm{PO}_{4}{ }^{3-}\right.$ groups) and mixed phosphates $\left(\mathrm{P}_{2} \mathrm{O}_{7}{ }^{4-}\right.$ and $\mathrm{PO}_{4}{ }^{3-}$ groups $)$ have been intensely studied as cathode materials for both LIB and more recently also for NIB applications. Interestingly, we found substantial differences in rate performances among the members of the pyrophosphate and the mixed phosphates family that could be explained based on their structural differences.

The lowest rate performance in this family of compounds is observed for the vanadium-based $\mathrm{NaVP}_{2} \mathrm{O}_{7}$ which crystallizes in space group $P 2_{1} / c$ with corner-sharing $\mathrm{PO}_{4}$ and $\mathrm{VO}_{6}$ groups (Fig. S4a, ESI $\dagger$ ). A previous study on this compound as a cathode material reported poor performance, achieving only $c a$. $35 \%$ of theoretical capacity $\left(108 \mathrm{~mA} \mathrm{~h} \mathrm{~g}^{-1}\right)$ even at low cycling rate of 0.05C. ${ }^{34}$ Detailed pathway analysis of this compound is discussed in Fig. S4b (ESI $\dagger$ ).

Among the $\mathrm{Na}_{2} \mathrm{MP}_{2} \mathrm{O}_{7}$ pyrophosphates with $\mathrm{M}=\mathrm{Fe}, \mathrm{Mn}$, $\mathrm{VO},{ }^{63,64,67,68}$ consistently somewhat higher rate capabilities are noted for the case $\mathrm{M}=\mathrm{Fe}$ (the rate performance data for three $\mathrm{Na}_{2-2 x} \mathrm{Fe}_{1+x} \mathrm{P}_{2} \mathrm{O}_{7}$ samples correspond to relaxation frequencies $W$ of $7-21 \mathrm{~h}^{-1}$ ) than for $\mathrm{M}=\mathrm{Mn}$ or $\mathrm{M}=\mathrm{VO}$ (both with $W \approx 2-4 \mathrm{~h}^{-1}$ ), while both perform significantly better than the V-compound described above (where the relaxation frequency can only be roughly estimated to $W \approx 0.04 \mathrm{~h}^{-1}$ due to the limited range of experimental data). A study of a $\mathrm{Na}_{2} \mathrm{FeP}_{2} \mathrm{O}_{7}-\mathrm{CNT}$ composite ${ }^{28}$ even suggests $W$ to be as high as $45 \mathrm{~h}^{-1}$. Here we explore the structural origin of such differences.

$\mathrm{Na}_{2} \mathrm{FeP}_{2} \mathrm{O}_{7}$, has only been characterized in 2012 independently by three research groups who reported different polymorphs - adopting either $P \overline{1}$ structure (Barpanda et al. ${ }^{65}$ and Honma et al. ${ }^{61}$ ) or $P 1$ structure (Kim et $a l .{ }^{62}$ ) with a reversible capacity of $90 \mathrm{~mA} \mathrm{~h} \mathrm{~g}^{-1}$ at $3.0 \mathrm{~V}\left(v s . \mathrm{Na} / \mathrm{Na}^{+}\right)$. The $\mathrm{Na}^{+}$pathway topology we found for $\mathrm{Na}_{2} \mathrm{FeP}_{2} \mathrm{O}_{7}$ starting from the $P \overline{\mathrm{1}}$ structural data of ref. 63 (see Fig. S5, ESI $\dagger$ ) is in excellent agreement with a previous computational study based on atomistic methods. ${ }^{64}$ Based on our BVSE analysis, long-range $\mathrm{Na}^{+}$transport in this compound is effectively two-dimensional in the (011) planes due to the high barrier $(0.83 \mathrm{eV})$ involved with Na1-i1 hop which acts as connection between adjacent (011) planes. $\mathrm{Na}^{+}$transport predominantly takes place in the $[0,1,-1]$ direction, involving ribbon-like 1D paths containing fully occupied Na2 and interstitial site i1, where i1 connects two adjacent Na2. Such Na2-i1 paths are the bottlenecks for 1D percolation, with a corresponding barrier $0.33 \mathrm{eV}$.

The "large tunnels" previously reported contain partially occupied Na4, Na5 and Na6. ${ }^{65}$ Within these tunnels, two symmetrically equivalent, adjacent energy local minima separated by a barrier of $<0.05 \mathrm{eV}$ are occupied by $\mathrm{Na} 6$ each (occupancy $1 / 3$ ), while Na4 position coincides with the saddle point (occupancy 1/3). This can be simplified by the description of a single Na type (hereby named 'Na4/6') with total occupancy 1.0, delocalised in this low energy region. On the other hand, Na5 sites are nearby with site energy $c a .0 .1 \mathrm{eV}$ higher than $\mathrm{Na} 4 / \mathrm{Na} 6$. In fact, the $\mathrm{Na} 5$ site energy is the highest among all occupied Na sites, suggesting that this is the least favourable site for $\mathrm{Na}^{+}$. This is in line with experimental observation that $\mathrm{Na} 5$ occupancy is 0.5 while that of $\mathrm{Na} 1, \mathrm{Na} 2, \mathrm{Na} 3$, and $\mathrm{Na} 4 / \mathrm{Na} 6$ is 1.0 .

The percolating $1 \mathrm{D}$ channels are subsequently connected by the large tunnels to form 2D network via the path between the relatively high energy (and hence low occupancy) Na5 sites. The partial occupancy of $\mathrm{Na}$ sites is crucial in lowering the effective energy barrier for 2D percolation via Na5-Na5 hops to $0.40 \mathrm{eV}$ yielding a more robust network when compared to isolated 1D paths. Based on the overall reaction pathway, $\mathrm{Na} 3$ is expected to constitute and additional source of $\mathrm{Na}^{+}$ions for extraction via a Na3-Na5 path with a moderate barrier of $0.46 \mathrm{eV}$ (these $\mathrm{Na} 3$ sites may be viewed as "side branches" to the main "large tunnels"). Indeed, in the desodiated phase $\beta-\mathrm{NaFeP}_{2} \mathrm{O}_{7}$ (SG: $\left.P \overline{1}\right), \mathrm{Na} 3$ site occupancy drops to $0.5{ }^{63}$ Two further members of the pyrophosphate family with $\mathrm{M}=\mathrm{Mn}\left(W=4.3 \mathrm{~h}^{-1}\right)$ and $\mathrm{VO}\left(W=2.9 \mathrm{~h}^{-1}\right)$ that exhibit lower rate performances than $\mathrm{Na}_{2} \mathrm{FeP}_{2} \mathrm{O}_{7}$ are briefly discussed in the ESI $\dagger$ (see Fig. S6).

To reinforce the importance of built-in sodium site vacancies towards rate performance, we turn to the recently reported sodium-deficient $\mathrm{Na}_{1.63} \mathrm{Co}_{1.13} \mathrm{P}_{2} \mathrm{O}_{7}\left(W=15 \mathrm{~h}^{-1}\right) .{ }^{36}$ We found the pathway topology to be similar to $\mathrm{Na}_{2} \mathrm{FeP}_{2} \mathrm{O}_{7}$ albeit with higher migration barriers ( $0.52 \mathrm{eV}$ for $1 \mathrm{D}, 0.61 \mathrm{eV}$ for $2 \mathrm{D})$. Despite similar migration barriers in both $\mathrm{Na}_{1.63} \mathrm{Co}_{1.13} \mathrm{P}_{2} \mathrm{O}_{7}$ and $\mathrm{Na}_{2} \mathrm{MnP}_{2} \mathrm{O}_{7}$, the former $\left(W=15 \mathrm{~h}^{-1}\right)$ is clearly outperforming the latter $\left(W=4.3 \mathrm{~h}^{-1}\right)$ at higher C-rates. While all sodium sites are fully occupied in $\mathrm{Na}_{2} \mathrm{MnP}_{2} \mathrm{O}_{7}, \mathrm{Na}_{1.63} \mathrm{Co}_{1.13} \mathrm{P}_{2} \mathrm{O}_{7}$ exhibits highly disordered sodium sites akin to the disordered $\mathrm{Na} 5$ and $\mathrm{Na} 4 / 6$ sites in $\mathrm{Na}_{2} \mathrm{FeP}_{2} \mathrm{O}_{7}$. Therefore, as we move from $\mathrm{Na}_{2} \mathrm{FeP}_{2} \mathrm{O}_{7}$ to $\mathrm{Na}_{1.63} \mathrm{Co}_{1.13} \mathrm{P}_{2} \mathrm{O}_{7}$, the minor decrease in $W$ is mainly related to the increasing migration barrier, while from $\mathrm{Na}_{1.63} \mathrm{Co}_{1.13} \mathrm{P}_{2} \mathrm{O}_{7}$ to $\mathrm{Na}_{2} \mathrm{MnP}_{2} \mathrm{O}_{7}$, further drop in $W$ is largely due to the diminishing availability of vacancies in sodium sites.

Our model of $\mathrm{Na}_{1.63} \mathrm{Co}_{1.13} \mathrm{P}_{2} \mathrm{O}_{7}$ also includes the excess $\mathrm{Co}^{2+}$ and presence of $\mathrm{Co}^{3+}$ to compensate for sodium deficiencies. Due to the higher BV sum of Co on Co1 this site is considered to contain a mixture of (redox inactive) $\mathrm{Co}^{3+}$ and $\mathrm{Co}^{2+}$ while the $\mathrm{Co} 2$ site is occupied by $\mathrm{Co}^{2+}$ in the sodiated form. The remaining excess $\mathrm{Co}^{2+}$ ions are assigned to the Na6 sites as suggested by ref. 36 . As these Na6 sites are side branches to the main percolating pathway, we do not expect the co-presence of $\mathrm{Co}^{2+}$ at these sites to block the sodium extraction. Interestingly, the unusually high value of $\alpha=20 \%$ of $\mathrm{Na}_{1.63} \mathrm{Co}_{1.13} \mathrm{P}_{2} \mathrm{O}_{7}$ (i.e. $20 \%$ of theoretical capacity inaccessible even at low C-rate) might suggest that these $\mathrm{Co}^{2+}$ ions at the $\mathrm{Na} 6$ sites, which should contribute to $c a .13 \%$ of the total theoretical capacity, are also redox-inactive.

The case of $\mathrm{Na}_{1.63} \mathrm{Co}_{1.13} \mathrm{P}_{2} \mathrm{O}_{7}$ highlights the strategy of offstoichiometry synthesis to improve the rate performance via disordered sodium sites throughout the (dis)charge cycle. 
Since $\mathrm{Na}_{2} \mathrm{FeP}_{2} \mathrm{O}_{7}$ has naturally disordered $\mathrm{Na} 4 / 6$ and Na5 sites, intuitively this strategy should have limited success here. Indeed, we find that the pathway characteristics in the related $\mathrm{Na}_{2-2 x} \mathrm{Fe}_{1+x} \mathrm{P}_{2} \mathrm{O}_{7}$, in particular the case of $\mathrm{Na}_{1.56} \mathrm{Fe}_{1.22}\left(\mathrm{P}_{2} \mathrm{O}_{7}\right)_{2},{ }^{66}$ are less favourable than in $\mathrm{Na}_{2} \mathrm{FeP}_{2} \mathrm{O}_{7}$ in two ways. Firstly, some of the corresponding migration barriers in $\mathrm{Na}_{1.56} \mathrm{Fe}_{1.22}\left(\mathrm{P}_{2} \mathrm{O}_{7}\right)_{2}$ are significantly increased. While the barrier for $1 \mathrm{D}$ percolation remains at $0.37 \mathrm{eV}$ (marginally higher than $0.33 \mathrm{eV}$ in $\mathrm{Na}_{2} \mathrm{FeP}_{2} \mathrm{O}_{7}$ ), the $2 \mathrm{D}$ barrier increases to $0.69 \mathrm{eV}$ (as compared to $0.40 \mathrm{eV}$ in $\mathrm{Na}_{2} \mathrm{FeP}_{2} \mathrm{O}_{7}$ ). Secondly, the link between the $1 \mathrm{D}$ channels now no longer occurs via Na5-Na5 hops, but rather via the long Na5-Na3-Na1-Na2 (following the same sodium site nomenclature as in $\mathrm{Na}_{2} \mathrm{FeP}_{2} \mathrm{O}_{7}$ ). Furthermore, the latter path is now susceptible to blocking as the Na1 site is partially occupied with $\mathrm{Fe}^{2+}$ in $\mathrm{Na}_{1.56} \mathrm{Fe}_{1.22}\left(\mathrm{P}_{2} \mathrm{O}_{7}\right)_{2}$. Therefore, the effectiveness of higher dimensionality pathway in $\mathrm{Na}_{1.56} \mathrm{Fe}_{1.22}\left(\mathrm{P}_{2} \mathrm{O}_{7}\right)_{2}$ is compromised by both blocking effects as well as the resulting higher migration barrier.

More recently, Kim et al. reported $\mathrm{Na}_{7} \mathrm{~V}_{3}\left(\mathrm{P}_{2} \mathrm{O}_{7}\right)_{4}$ as a $4 \mathrm{~V}$ cathode material for Na-ion battery. ${ }^{23}$ This compound retains an impressive relative capacity of $c a$. $80 \%$ even at $10 \mathrm{C}$ cycling rate and seems to have a second plateau of the relative capacity above this value, so that the fit yields the extraordinary value of $W \approx 141 \mathrm{~h}^{-1}$. Unsurprisingly, we found that this compound bears an unusually low migration barrier and contains vacant sites within the pathway. Our model reveals that $\mathrm{Na}_{7} \mathrm{~V}_{3}\left(\mathrm{P}_{2} \mathrm{O}_{7}\right)_{4}$ allows $\mathrm{Na}^{+}$conduction involving $\mathrm{Na} 3$ and $\mathrm{Na} 4$ in an extended $2 \mathrm{D}$ network in the $a b$-plane with a low migration barrier of $0.23 \mathrm{eV}$ ( $c f$. Fig. 8c). While all the sodium sites are reported experimentally to be fully occupied, the availability of low-lying interstitial sites i1 within the $2 \mathrm{D}$ backbone should aid the overall ionic transport. Furthermore, the polyanion framework
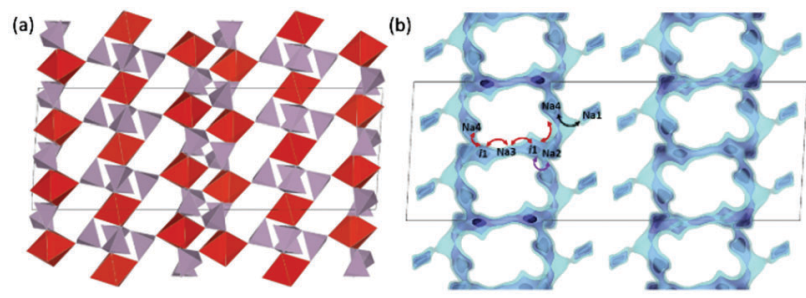

(c)

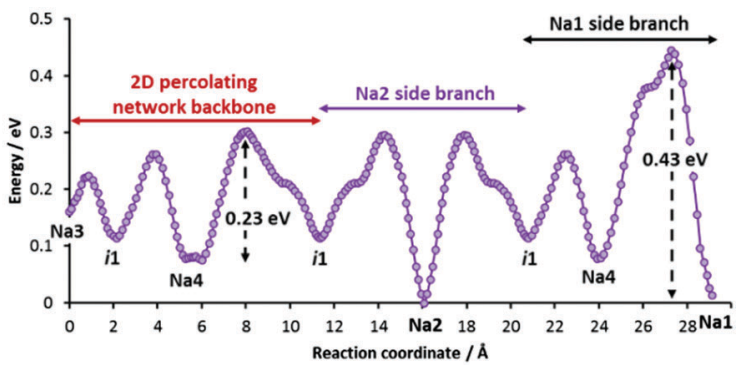

Fig. 8 (a) Crystal structure of $\mathrm{Na}_{7} \mathrm{~V}_{3}\left(\mathrm{P}_{2} \mathrm{O}_{7}\right)_{4}$ (SG: C2/C) and (b) energy isosurfaces representing $\mathrm{Na}^{+}$conduction pathway projected along $b$-direction. Black solid line highlights the unit cell. (c) Reaction pathway shows a 2D percolating network containing Na3, Na4 and involving a low barrier of $0.23 \mathrm{eV}$ as well as additional sodium ions ( $\mathrm{Na} 1, \mathrm{Na} 2)$ which are accessible via moderate migration barriers of $0.3-0.4 \mathrm{eV}$. intersperses with the 2D networks ( $c f$. Fig. 8a and b), in contrast to $\mathrm{NaMO}_{2}$-type layered compound where sodium ions constitute a whole layer between adjacent polyanion slabs. The more robust framework in the former therefore ensures a high mechanical stability against sodium extraction/insertion. This is also verified experimentally where the observed volume change is only $1 \% .^{23}$

An extension to the pyrophosphate family is the mixed phosphates involving $\left(\mathrm{PO}_{4}\right)^{3-}$ and $\left(\mathrm{P}_{2} \mathrm{O}_{7}\right)^{4-}$ polyanion groups (cf. Fig. S7a, ESI $\dagger$ ). Mixed phosphates of the general formula $\mathrm{Na}_{4} \mathrm{M}_{3}\left(\mathrm{PO}_{4}\right)_{2} \mathrm{P}_{2} \mathrm{O}_{7}\left(\mathrm{M}=\mathrm{Mn},{ }^{29} \mathrm{Fe}^{30,31}\right)$ have shown respectable rate capability as evidenced in Fig. 2. In both compounds, we found similar pathway topology consisting of interconnected 1D paths of low to moderate barriers to form an overall 3D percolating network for long-range ionic transport. The estimated migration barrier for at least 1D transport is only approximately $0.30 \mathrm{eV}$ and $0.28 \mathrm{eV}$ for $\mathrm{M}=\mathrm{Fe}$ and $\mathrm{M}=\mathrm{Mn}$, respectively ( $c f$. Fig. $\mathrm{S} 7 \mathrm{~b}$, ESI $\dagger$ ), in close agreement with an earlier molecular dynamics study. ${ }^{67}$ Higher-dimensional pathways are subsequently activated at higher barriers. This combination of energetic considerations clearly explains their superior performance over $\mathrm{Na}_{2} \mathrm{MnP}_{2} \mathrm{O}_{7}$ and $\mathrm{Na}_{2} \mathrm{VOP}_{2} \mathrm{O}_{7}$. However, there is a lack of readily available low energy vacant sites within the sodium ion pathways of these mixed phosphates that may explain the relatively high fraction of the theoretical capacity that cannot be realised even at low rates.

Another promising mixed phosphate compound is $\mathrm{Na}_{7} \mathrm{~V}_{4} \mathrm{PO}_{4}{ }^{-}$ $\left(\mathrm{P}_{2} \mathrm{O}_{7}\right)_{4}$ (SG: $\left.P \overline{4} 2_{1} c\right)$ as shown in Fig. 9a. ${ }^{32}$ Our pathway model in Fig. $9 \mathrm{~b}$ reveals that the overall conduction network consists of two independent networks (both long-range percolating): 1D paths along $c$-direction and 3D paths formed by linking crossshaped local clusters. These two networks are separated by a moderate barrier of $0.53 \mathrm{eV}$, while the effective migration barriers for the $1 \mathrm{D}$ and $3 \mathrm{D}$ network associated with long-range transport are $0.33 \mathrm{eV}$ and $0.46 \mathrm{eV}$, respectively ( $c f$. Fig. 9c). There is also a considerable amount of low-lying interstitial sites in the $\mathrm{Na} 2$ channels. A qualitative consideration of these factors thus reasonably qualifies this compound to have a rate performance on par with or better than the previously discussed mixed phosphates compounds. In relation to this, it should be noted that the rate performance shown in Fig. 2 for this compound is associated with nanosizing and hierarchical composite design. Nonetheless, this highlights the fact that a compound which has by default a decent rate capability without special optimizations stands a chance to compete with top contenders with elaborate particle morphology design.

Finally, the chemistry of pyrophosphates can be further enriched with the introduction of fluorides into the structure. The first sodium fluoropyrophosphate Na-ion battery cathode material with an open three-dimensional framework, $\mathrm{Na}_{4} \mathrm{NiP}_{2} \mathrm{O}_{7} \mathrm{~F}_{2}$ (SG: Imma), was reported by Kundu et al. ${ }^{68}$ and found to have a high average voltage of $c a .5 \mathrm{~V}$ although only the $\mathrm{Ni}^{2+/ 3+}$ redox couple could be activated limiting the theoretical capacity to about $75 \mathrm{~mA} \mathrm{~h} \mathrm{~g}{ }^{-1}$. Ab initio calculations by the same group suggest a low migration barrier of $0.36 \mathrm{eV}$ along the [010] direction and their experimental determination of the ionic conductivity (finding value of $0.32 \mathrm{eV}$ ) suggest that the material 

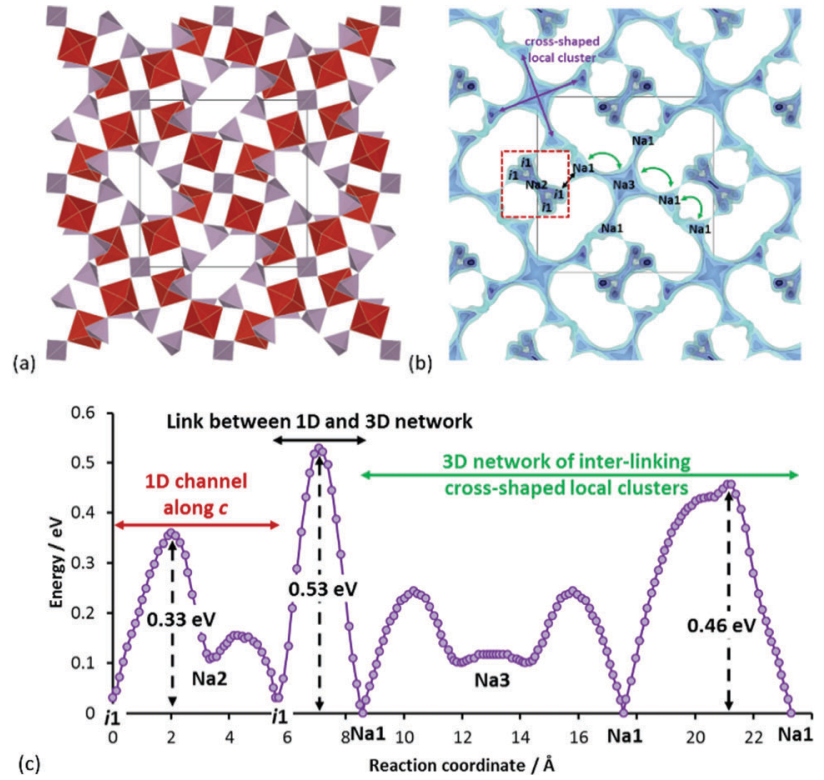

Fig. 9 (a) Crystal structure of $\mathrm{Na}_{7} \mathrm{~V}_{4} \mathrm{PO}_{4}\left(\mathrm{P}_{2} \mathrm{O}_{7}\right)_{4}$ (space group $P \overline{4} 2_{1} C$ ) and (b) energy isosurfaces representing $\mathrm{Na}^{+}$conduction pathway projected along $c$-direction. Black solid line and red dotted line highlight the unit cell and the 1D pathway along $c$ respectively. (c) Pathway topology of this compound can be described by the reaction graph where two conduction network (one 1D and the other 3D) are separated by a moderate barrier of $0.53 \mathrm{eV}$. The 3D network itself is made by inter-linking cross-like clusters where each cluster contains four identical Na1-Na3 local migration paths.

should be able to sustain high rate performance, though this remains to be experimentally verified. Details on the $\mathrm{Na}^{+}$paths in this compound can be found in the ESI $\dagger$ (see Fig. S8).

3.3.4. Antisite defect concentration effects in $\mathrm{Na}_{3} \mathrm{MnPO}_{4} \mathrm{CO}_{3}$. As an example of how defect formation can drastically alter the migration pathway, we studied $\mathrm{Na}_{3} \mathrm{MnPO}_{4} \mathrm{CO}_{3}$ which was first demonstrated by Ceder et al. as a sodium cathode material exhibiting a voltage of $3.7 \mathrm{~V}\left(v s . \mathrm{Na} / \mathrm{Na}^{+}\right)$, where both $\mathrm{Mn}^{2+} / \mathrm{Mn}^{3+}$ and $\mathrm{Mn}^{3+} / \mathrm{Mn}^{4+}$ redox couples were supposed to be redox active. ${ }^{42}$ $\mathrm{Na}_{3} \mathrm{MnPO}_{4} \mathrm{CO}_{3}$ adopts a layered structure constituting of cornersharing polyhedra of $\mathrm{PO}_{4}$ and $\mathrm{MnO}_{6}$ groups. $\mathrm{CO}_{3}$ groups that share two $\mathrm{O}$ with one $\mathrm{MnO}_{6}$ octahedron "dip" into the inter-layer space occupied by $\mathrm{Na}^{+}$ions (Fig. 10a). Similar to Eldfellite, $\mathrm{NaFe}\left(\mathrm{SO}_{4}\right)_{2}$, and $\mathrm{Na}_{2} \mathrm{FePO}_{4} \mathrm{~F}$ discussed above, the $\mathrm{Na}_{3} \mathrm{MnPO}_{4} \mathrm{CO}_{3}$ structure contains a two-dimensional $\mathrm{Na}^{+}$pathway formed by the connection of each $\mathrm{Na} 2$ site to four adjacent $\mathrm{Na} 2$ sites. Na1 sites are attached to the main percolating pathway (Fig. 10b, inset) as additional sources of $\mathrm{Na}^{+}$ions via two Na1-Na2 connections. As shown in Fig. 10b, moderate migration barriers were calculated for Na1-Na2 and Na2-Na2 hops $-0.66 \mathrm{eV}$ and $0.52 \mathrm{eV}$ respectively. Also, the energy plateau at the Na2 site may suggest high thermal displacements amplitudes, although there was no experimental anisotropic displacement data to confirm this.

The combination of high-dimensional pathway and moderate migration barriers (slightly above $0.5 \mathrm{eV}$ ) are in line with the observed relaxation frequency $\left(W=1.5 \mathrm{~h}^{-1}\right.$ similar to the one of $\mathrm{Na}_{2} \mathrm{FePO}_{4} \mathrm{~F}$ both in $W$ and migration barrier), but the absolute capacity is limited by an unusually large fraction of the

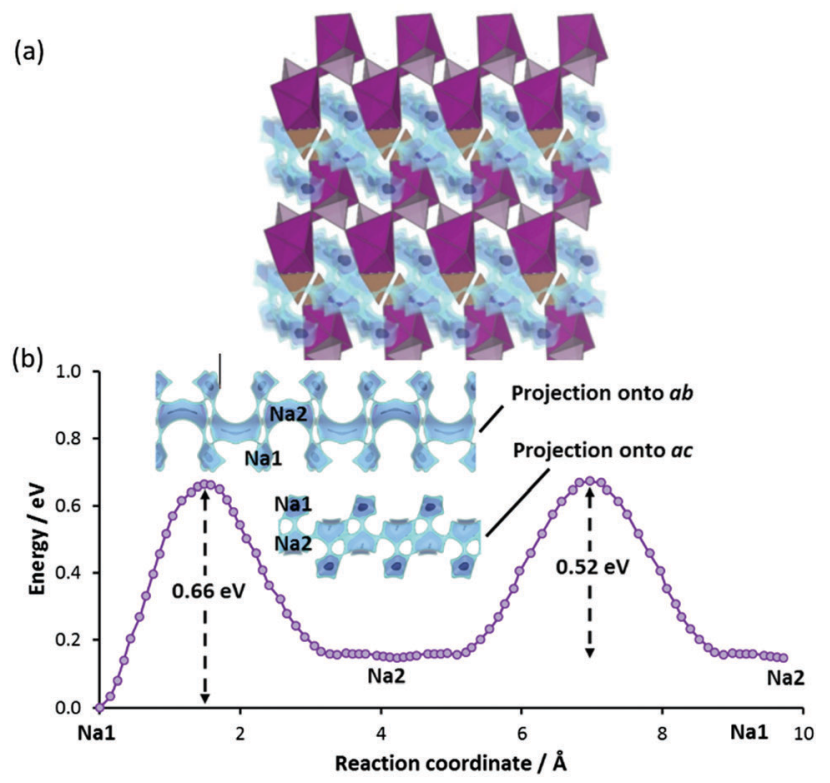

Fig. 10 (a) Crystal structure of Sidorenkite $\mathrm{Na}_{3} \mathrm{MnPO}_{4} \mathrm{CO}_{3}$ with energy isosurfaces between stacked slabs made of $\mathrm{PO}_{4}$ (light purple polyhedra), $\mathrm{MnO}_{6}$ (dark purple octahedra) and $\mathrm{CO}_{3}$ (brown triangle) groups. (b) Reaction pathway of a sodium ion in the $b-c$ plane (inset) for long-range transport.

theoretical capacity that remains inaccessible even at low $\mathrm{C}$ rates $(\alpha \approx 0.31)$. Assuming that $\mathrm{Na}(2)$ sites are fully extracted so that $\mathrm{Mn}$ is oxidised to $\mathrm{Mn}^{3+}$, achieving $100 \%$ of theoretical capacity (i.e. an oxidation to $\mathrm{Mn}^{4+}$ ) requires an extraction of $50 \%$ of the Na from Na1 sites, which involves a slightly higher barrier at $0.66 \mathrm{eV}$. The original authors already offered several possible reasons for the low capacity, including defects due to intense ball-milling. In a separate study, it was found that long ball-milling time caused excessive formation of both $\mathrm{Mn}^{2+}$ / $\mathrm{Na}(1)^{+}$and $\mathrm{Mn}^{2+} / \mathrm{Na}(2)^{+}$antisite defects (especially the latter) that in this structure are expected to reduce ionic conductivity and rate capability. ${ }^{69}$

To investigate the effects of such defect formation, we have created and relaxed two $2 \times 2 \times 2$ supercell structures containing these defects respectively. Interestingly, in both cases, we observe that the displaced $\mathrm{Na}_{\mathrm{Mn}}{ }^{\prime}$ ion facilitates the cross-linking of two adjacent conduction planes. One such example is shown in Fig. 11 for the case of a Mn/Na1 antisite defect, where the cross-linking path $\left(\mathrm{Na} 1-\mathrm{i}-\mathrm{Na}_{\mathrm{Mn}}-\mathrm{Na} 1\right)$ involves a moderate migration barrier of $c a$. $0.5 \mathrm{eV}$ comparable to the long-range transport barrier $0.52 \mathrm{eV}$ in the fully ordered structure. Therefore, these sodium ions at defect sites are expected to be equally extractable. The downside of this antisite defect formation is that it negatively affects the more important $\mathrm{Na} 2-\mathrm{Na} 2$ backbone of the long-range migration path. A $\mathrm{Mn}_{\mathrm{Na} 2} \cdot$ blocks four $\mathrm{Na} 2-\mathrm{Na} 2$ paths and four Na1-Na2 paths and $\mathrm{Mn}_{\mathrm{Na} 1}$ - raises the migration barrier of two out of the four adjacent Na2-Na2 paths significantly from $0.52 \mathrm{eV}$ to $0.75 \mathrm{eV}$ (cf. Fig. 11) due to the stronger Coulombic repulsion from doubly-charged $\mathrm{Mn}^{2+}$ and Coulomb attraction to a nearby $\mathrm{CO}_{3}$ group that is tilted towards $\mathrm{Mn}^{2+}$ (i.e. closer to the saddle points of the high-barrier Na2-Na2 paths). 


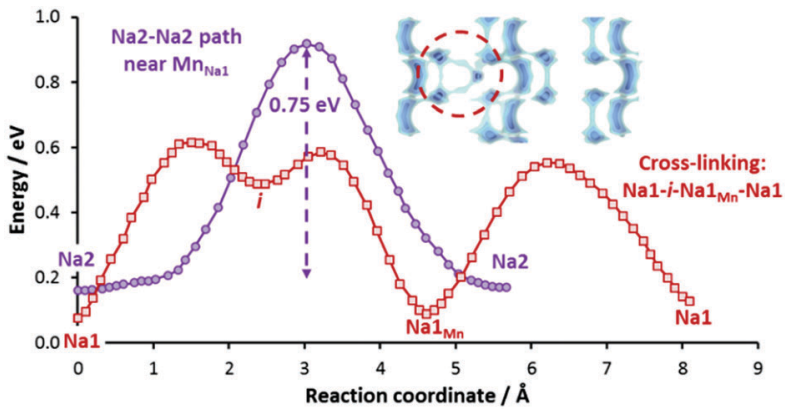

Fig. 11 Reaction pathway in the structure incorporating a Mn/Na1 antisite defect pair. The $\mathrm{Na}_{\mathrm{Mn}}$ ' defect allows cross-linking of adjacent 2D planes via $\mathrm{Na1}-\mathrm{i}-\mathrm{Na} 1_{\mathrm{Mn}}-\mathrm{Na1}$ path (red graph). Visualization of such cross-linking is highlighted in the dotted circle. At the same time, some $\mathrm{Na} 2-\mathrm{Na} 2$ paths become less accessible due to the higher barrier of $0.75 \mathrm{eV}$ in the vicinity of $\mathrm{Mn}_{\mathrm{Na} 1}$

Such a situation involving a sacrifice of backbone effectiveness for an increase in pathway dimensionality in other directions may be analogous to the previously studied case of $\mathrm{LiFePO}_{4}$, where a small concentration of $\mathrm{Li} / \mathrm{Fe}$ antisite defects allows for crosslinking of neighbouring $\mathrm{Li}$ extraction of channels, while an excessively high antisite defect concentration renders the material electro-inactive by blocking the backbone of the ion paths. $^{70,71}$ It is therefore important, in the design of high rate capability electrode materials, to study antisite defect formation involving sodium sites, especially those which participate in the overall ionic conductivity.

3.3.5. NASICON type compounds and the role of vacant sites in the migration path. One obvious requirement for ion transport in solids that we have only briefly discussed so far is the presence of unoccupied sites that have comparably low site energies as the occupied sites, i.e. vacancies on the regularly occupied sites or low-energy interstitials. Among the compounds with relatively high rate performance, the alluaudite $\mathrm{Na}_{2+2 x} \mathrm{Fe}_{2-x}\left(\mathrm{SO}_{4}\right)_{3}$ discussed above in Section 3.3.1 contains a large fraction of vacancies $(50 \%$ of the $\mathrm{Na} 3$ sites, $25 \%$ of the $\mathrm{Na} 2$ sites). We have seen in the pyrophosphates that disordered sodium sites (e.g. Na4/6 and Na5 in $\left.\mathrm{Na}_{2} \mathrm{FeP}_{2} \mathrm{O}_{7}\right)$ and low-lying interstitial sites (e.g. $\left.\mathrm{Na}_{7} \mathrm{~V}_{3}\left(\mathrm{P}_{2} \mathrm{O}_{7}\right)_{4}\right)$ also contribute towards high rate performance.

In this section, we reinforce our argument by focusing on another structure type that contains a high fraction of unoccupied sites within the pathways: the "Na superionic conductor" (NASICON) structure type $\mathrm{Na}_{3} \mathrm{M}_{2}\left(\mathrm{PO}_{4}\right)_{3}$. In the rhombohedral high temperature $\beta$ phase (space group $R \overline{3} c$ ) the NASICON structure contains a 3D network of interstitial spaces of a size particularly suitable for $\mathrm{Na}^{+}$ion diffusion. ${ }^{72,73}$

Among the $\mathrm{Na}_{3} \mathrm{M}_{2}\left(\mathrm{PO}_{4}\right)_{3}$ compounds, we will discuss here the example of $\mathrm{Na}_{3} \mathrm{~V}_{2}\left(\mathrm{PO}_{4}\right)_{3}$ that gained particular attention due to the ability to exchange more than $1 \mathrm{Na}^{+} / \mathrm{e}^{-}$per transition metal ion. The compound displays three potential plateaux located at $3.4,1.6 \mathrm{~V}$ and $0.3 \mathrm{~V}$ vs. $\mathrm{Na} / \mathrm{Na}^{+}$, where the highest potential is related to the oxidation of $\mathrm{V}^{3+}$ to $\mathrm{V}^{4+}$ in $\mathrm{Na}_{1} \mathrm{~V}_{2}\left(\mathrm{PO}_{4}\right)_{3}$ that is accompanied by a moderate volume contraction $(7.4 \%$ of unit cell volume). ${ }^{74-76}$ The lower two potential plateaux corresponding to the stepwise reduction of $\mathrm{V}^{3+}$ to $\mathrm{V}^{2+}$ in $\mathrm{Na}_{4} \mathrm{~V}_{2}\left(\mathrm{PO}_{4}\right)_{3}$ and finally $\mathrm{Na}_{5} \mathrm{~V}_{2}\left(\mathrm{PO}_{4}\right)_{3}$ will not be discussed here as the low voltage makes them more suitable for anode applications.

Lim et al. ${ }^{75}$ suggested that the rhombohedral phase is retained and $\mathrm{Na}(1)$ remains fully occupied while the $\mathrm{Na}(2)$ site is electrochemically active when $\mathrm{Na}_{x} \mathrm{~V}_{2}\left(\mathrm{PO}_{4}\right)_{3}$ is desodiated from $x=3$ to $x=1$ and that this oxidation should occur as a two-phase reaction. Jian et al. ${ }^{77}$ find that both Na site types are partially occupied in $\mathrm{Na}_{3} \mathrm{~V}_{2}\left(\mathrm{PO}_{4}\right)_{3}$ with a 0.843 occupancy of the $6 \mathrm{~b}$ site (M1) and a 0.719 occupancy of the $18 \mathrm{e}$ site (M2) at room temperature and that lowering the temperature to about $100 \mathrm{~K}$ would be necessary to for a full occupancy of M1 site (reducing the M2 site occupancy to 2/3). In $\mathrm{Na}_{1} \mathrm{~V}_{2}\left(\mathrm{PO}_{4}\right)_{3}$ the $\mathrm{M} 2$ site is completely desodiated, whereas the site occupancy factor of M1 increases to 0.94 (the location of remaining $0.06 \mathrm{Na}$ could not be identified).

Our pathway model for $\mathrm{Na}_{3} \mathrm{~V}_{2}\left(\mathrm{PO}_{4}\right)_{3}$ as shown in Fig. 12 demonstrates that $\mathrm{Na}^{+}$migrates through the 3D-percolating network by consecutive M1-M2-M1 hops. A barrier of $0.39 \mathrm{eV}$ is calculated for the sodiated phase, in good agreement with a recent $a b$ initio study. ${ }^{78}$ For the fully desodiated phase with vacant M2 sites both the migration barrier and the site energy difference between M1 and M2 sites increase by about $0.07 \mathrm{eV}$. It may be noted in passing that the pathway for the sodiated phase involves a plateau-like energy region between M1 and the saddle point, which is reminiscent of the 'third sodium site' M3 in previous NASICON structure refinements where the Na density distribution on the essentially fully occupied M1 site is described by $\mathrm{Na}^{+}$partially occupying both $\mathrm{M} 1$ and nearby

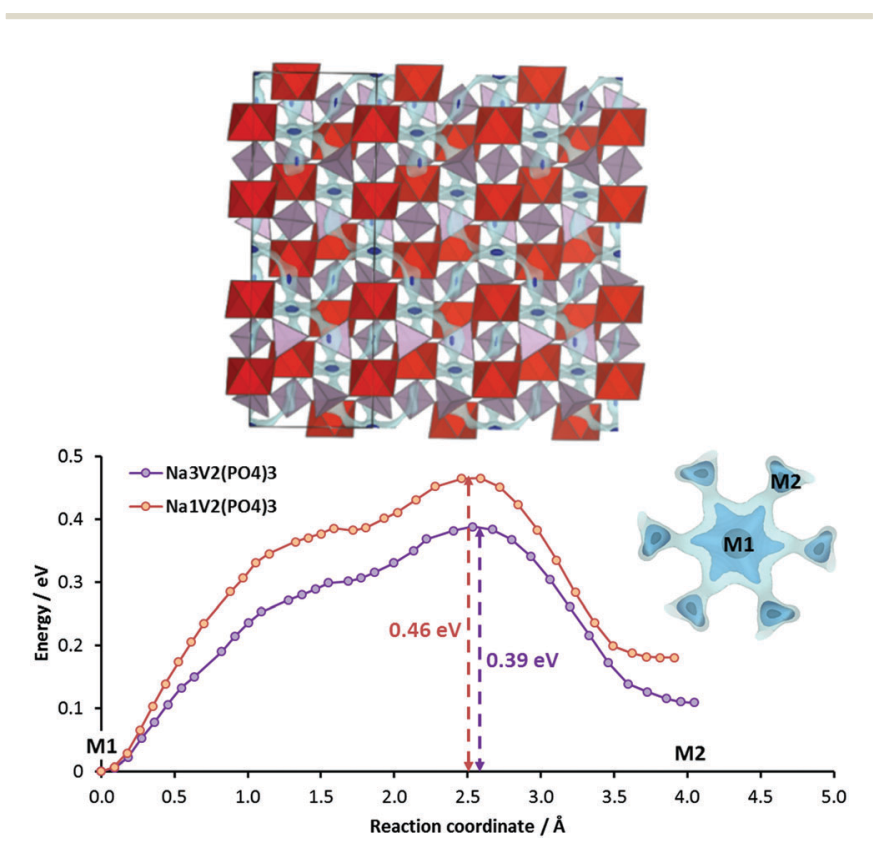

Fig. 12 Top: NASICON-type structure of $\mathrm{Na}_{3} \mathrm{~V}_{2}\left(\mathrm{PO}_{4}\right)_{3}$ with energy isosurfaces showing 3D $\mathrm{Na}^{+}$pathway interweaving the polyanionic framework of $\mathrm{PO}_{4}$ (red octahedra) and $\mathrm{VO}_{6}$ (purple) groups. Unit cell is shown by the black rectangle. Bottom: Migration pathways of $\mathrm{Na}^{+}$within the 3D network involving M1-M2-M1 hops with moderate barrier energy of $0.39 \mathrm{eV}$ and $0.46 \mathrm{eV}$ for the sodiated and desodiated phases respectively. The M2 site energy increases as the structure gets desodiated. Inset shows that each $M 1$ site is connected to six adjacent $M 2$ sites. 
M3 sites. ${ }^{79}$ Since the energy minimum is very shallow, we adopt the simpler model involving only M1 and M2 sites.

Based on the increasing site preference of $\mathrm{Na}^{+}$for the M1 site with decreasing sodium content as seen in Fig. 12, the redistribution of some $\mathrm{Na}^{+}$from M2 to M1 sites during desodiation appears plausible, as the difference in $E_{\mathrm{BVSE}}(\mathrm{Na})$ between these sites increases from 0.11 to $0.18 \mathrm{eV}$. Based on recent structure refinements an earlier model of a two-step desodiation with equal occupancy of both Na sites at all stages of desodiation was revived in the literature, ${ }^{80,81}$ but such a model can be clearly ruled out from the observed energy profiles. The recent experimental observation that the anyways favourable power performance is substantially enhanced further by slight Mg-doping in $\mathrm{Na}_{3} \mathrm{~V}_{1.95} \mathrm{Mg}_{0.05}\left(\mathrm{PO}_{4}\right)_{3}{ }^{82}$ can also be rationalised from our pathway model. $\mathrm{Mg}$ doping on the vanadium site limits desodiation to $\mathrm{Na}_{1.1} \mathrm{~V}_{1.95} \mathrm{Mg}_{0.05}\left(\mathrm{PO}_{4}\right)_{3}$ preventing a complete ordering of $\mathrm{Na}$ on the $\mathrm{Na}(1)$ site which would be the power performance-limiting stage during deep cycling.

Although other (electronically insulating) NASICON variants such as $\mathrm{Na}_{3} \mathrm{Zr}_{2}\left(\mathrm{SiO}_{4}\right)_{2}\left(\mathrm{PO}_{4}\right)$ have exhibited much lower activation energy of $0.2-0.35 \mathrm{eV}$, the moderate barrier in $\mathrm{Na}_{3} \mathrm{~V}_{2}\left(\mathrm{PO}_{4}\right)_{3}$ $(0.39 \mathrm{eV})$ coupled with the robust $3 \mathrm{D}$ pathway with numerous built-in vacancies justify a high rate capability of this compound $\left(W \approx 95 \mathrm{~h}^{-1}\right)$. It should be emphasized that an analysis focusing on just one of the criteria is not sufficient to make a useful prediction of rate performance: when comparing the pyrophosphates e.g. $\mathrm{Na}_{4} \mathrm{Mn}_{3}\left(\mathrm{PO}_{4}\right)_{2} \mathrm{P}_{2} \mathrm{O}_{7}\left(W=54 \mathrm{~h}^{-1}\right)$ and $\mathrm{Na}_{3} \mathrm{~V}_{2}\left(\mathrm{PO}_{4}\right)_{3}\left(W=95 \mathrm{~h}^{-1}\right)$ just based on the migration barriers within the pathways a similar power performance would be expected. However, $\mathrm{Na}_{3} \mathrm{~V}_{2}\left(\mathrm{PO}_{4}\right)_{3}$ retains relatively higher capacity for the 10-100C range. Such a decent rate capability is believed to originate from the built-in sodium site vacancies, so that the activation energy for ion transport does not need to include a defect formation component. Even in the fully sodiated NASICON phase there is already a significant amount of vacancies in the pathway network, corresponding to one-third of the total sites $(\mathrm{M} 1+\mathrm{M} 2)$. This and not the migration energy alone distinguishes such good ionic conductors (or high rate performance electrode materials) from most other compounds for which all the low energy sites in the pathways sites are fully occupied. The high concentration of vacancies facilitates long-range ion transport by ensuring high success rate for ion hops. It is of course a wellestablished strategy to induce the formation of vacancies at alkali ion sites via aliovalent doping to improve ionic conductivity. ${ }^{83} \mathrm{We}$ believe the presence of sodium site vacancies in $\mathrm{Na}_{3} \mathrm{~V}_{2}\left(\mathrm{PO}_{4}\right)_{3}$ contributes to the considerable capacity at high C-rate.

3.3.6. Case study on sodium fluorophosphate $\mathrm{Na}_{3} \mathrm{~V}_{2}\left(\mathrm{PO}_{4}\right)_{2} \mathrm{~F}_{3}$. $\mathrm{Na}_{3} \mathrm{~V}_{2}\left(\mathrm{PO}_{4}\right)_{2} \mathrm{~F}_{3}$ (Fig. 13a) is currently one of the most intensely studied compound for use as NIB cathode material as it displays high voltage $\left(3.8 \mathrm{~V} v s . \mathrm{Na}^{+} / \mathrm{Na}\right)$ and reversible specific capacity at $120 \mathrm{~mA} \mathrm{~h} \mathrm{~g}^{-1},{ }^{84}$ close to theoretical capacity of $128 \mathrm{~mA} \mathrm{~h} \mathrm{~g}^{-1}$. Our pathway model based on the recently reported structure for $\mathrm{Na}_{3} \mathrm{~V}_{2}\left(\mathrm{PO}_{4}\right)_{2} \mathrm{~F}_{3}$ refined in space group Amam indicates that $\mathrm{Na}^{+}$ conduction pathway is strictly $2 \mathrm{D}$ as shown in Fig. 13a and b. ${ }^{85}$ This is in line with the DFT study from ref. 86, but in contrast with an earlier DFT study, which suggested "3D ions (a)

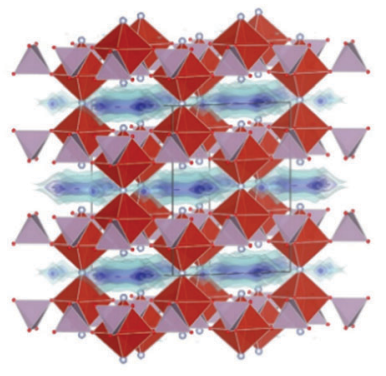

(b)
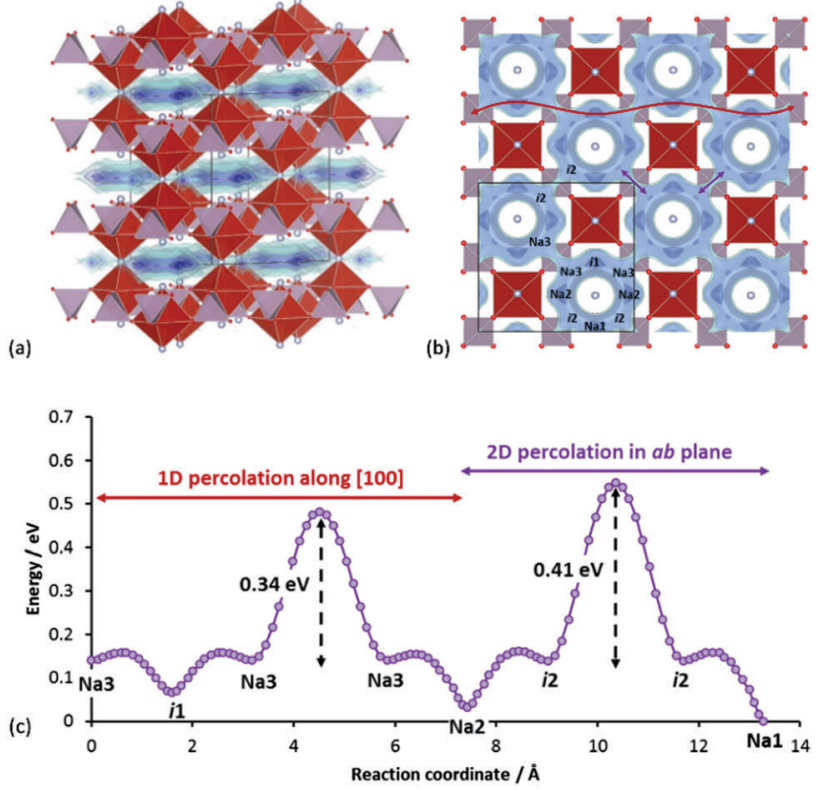

Fig. 13 (a) Crystal structure of $\mathrm{Na}_{3} \mathrm{~V}_{2}\left(\mathrm{PO}_{4}\right)_{2} \mathrm{~F}_{3}$ in the Amam space group, containing layered $\mathrm{Na}^{+}$conduction pathways (shown as energy isosurfaces) (b) projection along $\mathrm{c}$-axis showing energy isosurfaces of $\mathrm{Na}^{+}$ pathways involving interconnected ring-like local loops via Na3-Na3 path (bottleneck for 1D percolation) and i2-i2 path (bottleneck for 2D percolation) (c) reaction pathway showing relevant barriers involved in the 2Dpercolating network.

transport tunnels", ${ }^{87}$ It is unlikely that such differences are due to different structure models (Amam vs. $P 4_{2} / \mathrm{mnm}$ ), as our analysis based on the $\mathrm{P4}_{2} / \mathrm{mnm}$ and the Amam models produced similar findings. Below we explore the pathway in the Amam structure model to understand how $\mathrm{Na}_{3} \mathrm{~V}_{2}\left(\mathrm{PO}_{4}\right)_{2} \mathrm{~F}_{3}$ qualifies as a top contender in the high rate performance group.

According to our calculations, the $\mathrm{Na}^{+}$pathways in $\mathrm{Na}_{3} \mathrm{~V}_{2}\left(\mathrm{PO}_{4}\right)_{2} \mathrm{~F}_{3}$ show a slight in-plane anisotropy, where "ring-like" local pathway loops are interconnected via Na3-Na3 sodium sites and i2-i2 interstitial sites. The Na3-Na3 path was found to have lower barrier, leading to $1 \mathrm{D}$ percolation first prior to $2 \mathrm{D}$ percolation via i2-i2 path. As the site energy increases from Na1 $(0 \mathrm{eV})$ to $\mathrm{Na} 2(0.03 \mathrm{eV})$ to $\mathrm{Na} 3(0.14 \mathrm{eV})$, occupancy decreases from Na1 (1.0) to Na2 (0.65) to Na3 (0.30). We found also two other relevant unoccupied energy sites $(\mathrm{i} 1, \mathrm{i} 2)$ at $(0.250,0.031,0.500)$ and $(0.104,0.396$, $0.500)$ respectively. The labelled crystallographic sites, relative site energies and the corresponding migration barriers among all the energy sites are shown in Fig. 13b and c. Also, the average number of sodium ions in a ring approximates three (since the multiplicity of $\mathrm{Na} 2$ and $\mathrm{Na} 3$ sites is 2 and the site occupancies sum $\approx 1.0$ ).

Interestingly, this compound mimics the excellent ionic conductor beta-alumina in two ways. Firstly, both compounds exhibit fast $\mathrm{Na}^{+}$motions in a two-dimensional pathway, although strictly speaking in $\mathrm{Na}_{3} \mathrm{~V}_{2}\left(\mathrm{PO}_{4}\right)_{2} \mathrm{~F}_{3}$ this facile motion is limited to within each ring. Secondly, both compounds utilize a $2 \mathrm{D}$ conduction pathway which is contained within a three-dimensionally connected polyanionic framework, unlike layered $\mathrm{Na}_{x} \mathrm{MO}_{2}$ where the transition metal slabs are completely separated from 
each other. In $\mathrm{Na}_{3} \mathrm{~V}_{2}\left(\mathrm{PO}_{4}\right)_{2} \mathrm{~F}_{3}$, the inter-transition metal layer connection is made via a shared $\mathrm{F}^{-}$ion between two $\mathrm{VO}_{4} \mathrm{~F}_{2}$ groups. This may also explain the low volume change $(\sim 2 \%)$ upon cycling, ${ }^{84}$ since the $\mathrm{Na}^{+}$ions play less of a role in supporting the structure mechanically during cycling, in contrast to the case of layered $\mathrm{Na}_{x} \mathrm{MO}_{2}$.

With a "liquid-like" low energy pathway within each local loop (average local barriers $=0.11 \mathrm{eV}$ ), it is anticipated that intra-ring ionic motion will be highly correlated. Hops targeting occupied sites may still be successful, if the ion at the target site can be pushed across the low barrier to another position within the ring and $\mathrm{Na}^{+}$that fails to hop to a fully occupied adjacent ring can quickly rearrange itself in the current ring to find an alternative "exit" to another adjacent ring that can accommodate it. Intuitively, this promotes the effectiveness of the 2D network in terms of sodium extraction.

\subsection{Design guidelines from correlations between rate performance and pathway characteristics}

So far we have essentially demonstrated the relevance of three qualitative materials design criteria for high rate performance electrodes: low migration barrier in at least one direction, high pathway dimensionality and a sufficient excess number of low energy sites for the mobile species. Here we aim to proceed beyond such a qualitative treatment by establishing a quantitative figure of merit that allows us to directly predict the achievable rate capability for a given structure type. In doing so we utilize the characteristic C-rate $W$, i.e. the C-rate where the capacity drops to $1 / e$ of its low rate value and the stretching exponent $\beta$ that both have been introduced in eqn (5a) (see Section 3.1). Fig. 14 implies that for the covered range of sodium cathode materials the value of $W$ can be empirically correlated, as shown in eqn (13), to an activation term involving the ratio between activation energy and effective pathway dimensionality to the power of 1.5

$$
W=f_{1}(l) \exp \left[-f_{2} \frac{E_{\mathrm{A}}}{d^{1.5} k_{\mathrm{B}} T}\right]
$$

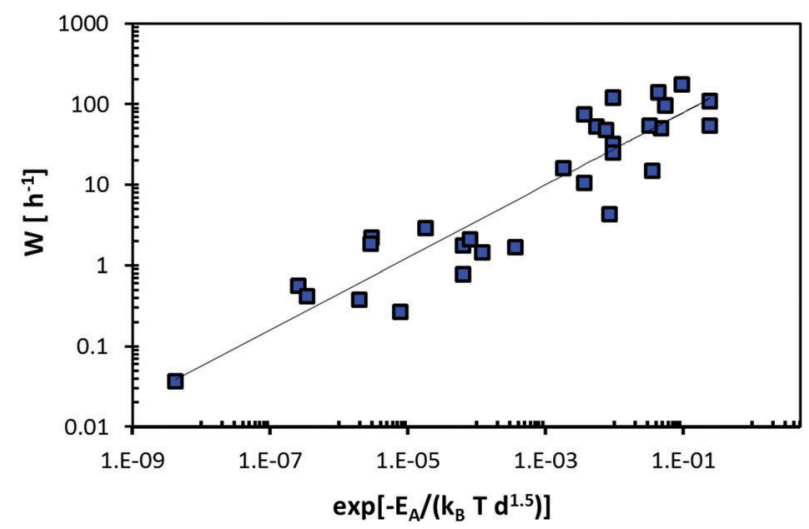

Fig. 14 Dependence of the achievable critical C-rate $W$, the relevant migration barrier height $E_{\mathrm{A}}$ and the effective pathway dimensionality $d$. The straight line in the double-logarithmic plot indicates the regression according to the fit function of eqn (13). with $f_{1}(l)=221 \mathrm{~h}^{-1}$ and $f_{2}=0.45$, if $W$ is given in $\mathrm{h}^{-1}$ and $k_{\mathrm{B}}$ is the Boltzmann constant.

From Fig. 14 it may e.g. be concluded that in order to achieve a rate capability corresponding to $W>10 \mathrm{~h}^{-1}$ (in other words a capacity $>37 \%$ of the low rate capacity at a C-rate $>10 \mathrm{C}$ ), the ratio of migration barrier to pathway dimensionality $E_{\mathrm{A}} / d^{1.5}$ should be smaller than ca. $0.15 \mathrm{eV}$. A significant part of the remaining scatter in Fig. 14 will be due to the different particle sizes $l$ of the samples from the underlying experimental literature reports. The scatter of experimental conditions, a probably relatively narrow range of particle sizes and incomplete data in the experimental literature reports did not permit to empirically include the particle size into eqn (11) for all the systems. Still the coefficient $f_{2} \approx 0.5$ can be understood as a signature of the correlation between the diffusion length and the square root of the activation energy for the diffusion.

The example of particle-size dependent rate-capability data for $\mathrm{Na}_{3}(\mathrm{VO})_{2}\left(\mathrm{PO}_{4}\right)_{2} \mathrm{~F}$ from ref. 88-91, shown in Fig. 15 emphasizes that $W$ will follow a $W \propto l^{-\gamma}$ dependence on the median particle size $l$ that constitutes an approximate measure of the required diffusion length inside the particle. For the case of Fig. 15 the exponent $\gamma$ is 1.2 . The necessary diffusion length for completion of the (de)sodiation reaction will also depend on the particle shape as well as for compounds with low-dimensional pathways on the orientation of the transport pathways relative to the long and short particle extensions. Therefore, it must be expected that the pathway tortuosity exponent $\gamma$ will depend on the pathway dimensionality. The diffusion length will, as discussed above, in compounds with one-dimensional conductors also be strongly influenced by the concentration of blocking defects (see e.g. also ref. 70, 71 and 92).

Based on the assumption that diffusion inside the cathode material limits the rate performance, it is obvious that the achievable rate performance of the cathode materials will also depend on temperature as expressed in eqn (13). Thus, testing the temperature of the rate performance may serve as a

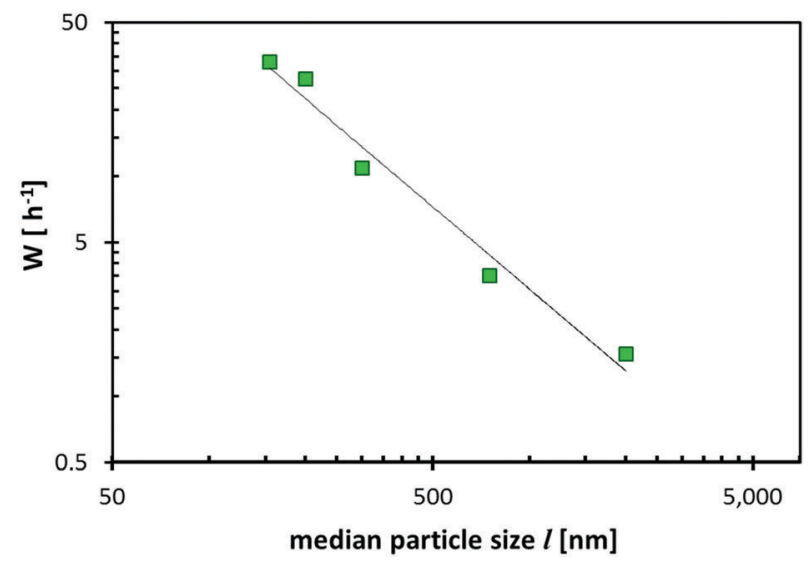

Fig. 15 Dependence of the achieved critical C-rate $W$ in $\mathrm{Na}_{3}(\mathrm{VO})_{2}\left(\mathrm{PO}_{4}\right)_{2} \mathrm{~F}$ on the median particle size as an approximate measure value for the length of the effective ion diffusion inside the particle. Data points refer to fits to the rate performances reported in four literature studies. ${ }^{88-91}$ The solid line corresponds to a power law fit $W \propto l^{-\gamma}$. 


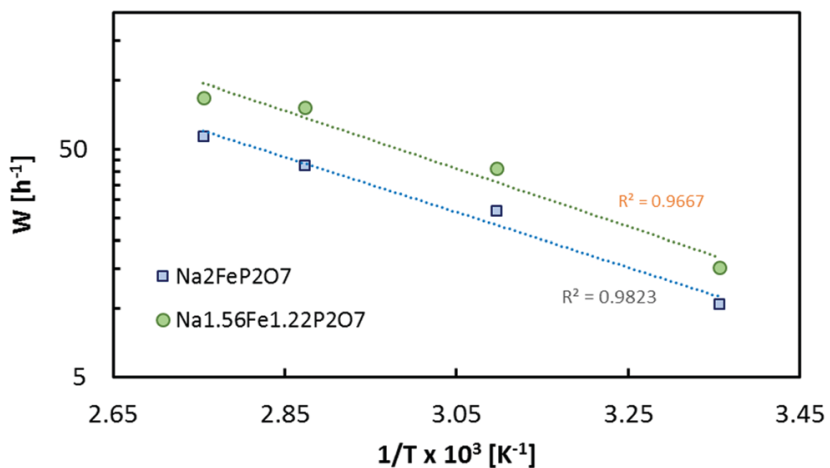

Fig. 16 Dependence of the achieved critical C-rate $W$ in two selected pyrophosphate compounds on the operating temperature. Data points refer to fits to the rate performances reported in ref. 27 . The dotted lines correspond to a $W=c e^{-b / T}$ fit.

plausibility test. As an example, data from ref. 27 for $\mathrm{Na}_{2} \mathrm{FeP}_{2} \mathrm{O}_{7}$ and $\mathrm{Na}_{1.56} \mathrm{Fe}_{1.22} \mathrm{P}_{2} \mathrm{O}_{7}$ confirm that the temperature dependence of the rate performance can be expressed by the exponential relationship between $W$ and $T$ ( $c f$. Fig. 16)

$$
W=f_{1} \mathrm{e}^{-A / k_{\mathrm{B}} T},
$$

where $f_{1}$ and $A$ are positive constants. As seen from Fig. 16 these two compounds with similar pathway topology and migration barriers will also exhibit a similar temperature dependence of their rate performance that may be related to the activation energy $E_{\mathrm{A}}$ and pathway dimensionality $d$ as the key descriptors of the pathway network. Taking $\mathrm{Na}_{2} \mathrm{FeP}_{2} \mathrm{O}_{7}$ as an example, a doubling of $W$ from 10 to $20 \mathrm{~h}^{-1}$ already requires a temperature increase from $25{ }^{\circ} \mathrm{C}$ to $45{ }^{\circ} \mathrm{C}$.

Besides $W$, the value of the stretching exponent $\beta$ in eqn (5a) also represents a structural feature. Essentially it relates to how complex the transport process will be. In more ordered compounds where defect formation and defect migration have to be considered and most attempted hops will be unsuccessful, a value of $\beta \approx 0.5$ is to be expected, while in "fast-ion conductors" with a high concentration of mobile defects (which may be interstitial ions of or vacant low energy sites for the mobile species) it will approximate $\beta \approx 1$ as the creation of additional defects plays no significant role for the anyways high success rate of elementary migration steps for mobile ions with sufficient kinetic energy. Indeed Fig. 17 shows a transition from $\beta \approx 0.5$ to a value close to $\beta \approx 1$ as a function of the "defect concentration", which for the sake of simplicity is here just taken as the sum of the interstitial $\mathrm{Na}^{+}$ions and the number of vacant low energy Na sites, relative to the number of Na per unit cell. More refined measures for the "defect concentration" may further reduce the scatter of the values.

A maybe not so intuitive consequence of the different stretching exponent values $\beta$ for different cathode materials may be worth noting. It implies opposite design guidelines for batteries and battery-supercapacitor hybrid systems (pseudo-capacitors). Pseudo-capacitors operate at high C-rates $\gg W$ and therefore it will be advantageous to choose materials for which the exponent $\beta$ is low (ideally 0.5 ), whereas for high rate batteries operating at rates just below $W$ it is crucial to use a material with $\beta \approx 1$ to

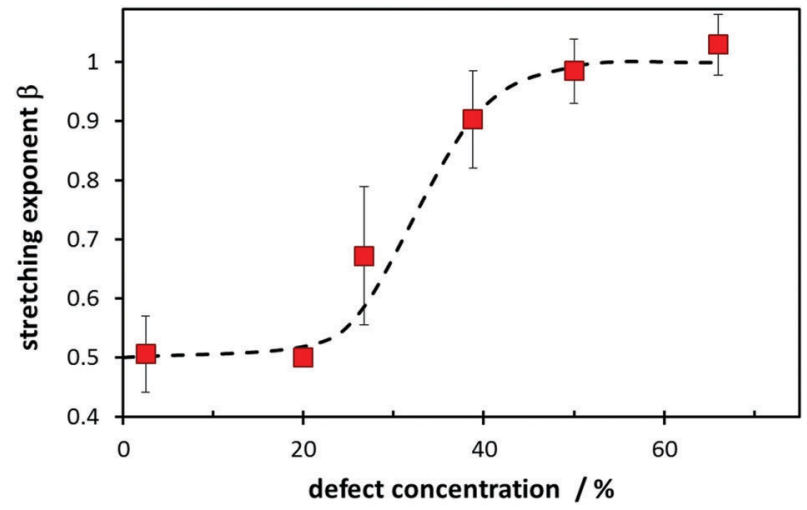

Fig. 17 Dependence of the stretching exponent $\beta$ on the number of defects of the mobile species relative to the number of sodium ions per formula unit for the studied compounds. To reduce experimental scatter results for compounds with similar defect concentrations are averaged. Error bars indicate the standard deviation of this average. The broken line is a guide to the eye.

retain a high capacity. At a rate of $W / 4$ a material with $\beta=0.5$ e.g. retains only $61 \%$ of its capacity, while for $\beta=1$ it would retain $78 \%$ of its low-rate capacity. When operated at a rate of $4 W$ a material with $\beta=0.5$ still has $13.5 \%$ of its low-rate capacity whereas for a material with $\beta=1$ the capacity dropped already to $1.8 \%$ of its low-rate value. For battery materials with highdimensional pathways but low defect concentrations (and hence $\beta \approx 0.5$ ) the capacity at C-rates slightly below $W$ can be significantly enhanced by introducing redox-inactive aliovalent dopants that boost the defect concentration (while in compounds with low-dimensional pathways this holds only if the dopants do not block the pathways).

The third empirical parameter $\alpha$, i.e. the fraction of the not realised theoretical capacity at low rates comprises a variety of effects such as interfacial kinetics, pathway blocking by impurities, chemical incompatibilities of cathode components, SEI formation, low electronic conductivity, volume changes and phase transitions during (de)sodiation etc. so that we cannot expect to derive a strong correlation to any structural feature. Still, it is observed that a high pathway dimensionality, low activation energy (and thus a high $W$ value) tends to favour a low $\alpha$ value, i.e. an almost complete utilisation of the theoretical capacity.

\section{Conclusions}

In this work, we have proposed to quantify the rate performances of sodium cathode materials in half-cells using the stretched exponential function. This allows a systematic comparison among different compounds in terms of the critical C-rate $W$, inaccessible fraction of theoretical capacity $\alpha$, and defect concentrationdependent $\beta$. We have also shown that $W$ is fundamentally related to the underlying structural features as they in turn determine the pathway topology, which can be characterized by two main descriptors: limiting migration barrier $E_{\mathrm{A}}$ and pathway dimension $d$. The dependence of $W$ on particle size and temperature is also demonstrated. We believe our work would facilitate a deeper understanding of the various contributing factors 
towards the overall rate capability and provide a systematic guideline for future designs of high rate performance NIBs.

\section{Glossary of main symbols}

$A$
$b_{\mathrm{A}-\mathrm{X}}$
$C$
$d$
$D_{0}$
$E_{\mathrm{A}}$
$E_{\mathrm{BVSE}}$
$E_{\mathrm{repulsion}}$
$e$
$f, f_{1}, f_{2}$
$I$
$k$
$k_{\mathrm{B}}$
$l$
$P(C)$
$q_{\mathrm{A}}, q_{\mathrm{B}}$
$Q(C)$
$Q_{\mathrm{rel}}(C)$
$Q_{\mathrm{theoretical}}$
$r_{\mathrm{A}}, r_{\mathrm{B}}$
$R_{\mathrm{A}-\mathrm{X}}$
$R_{0, \mathrm{~A}-\mathrm{X}}$

$\mid \Delta V$

$s_{\mathrm{A}-\mathrm{X}}$

Numerical factor

Bond valence parameter

Discharge rate

Dimension of percolating pathway for $\mathrm{Na}^{+}$ionic conduction

Bond breaking energy

Ion migration barrier

Bond valence site energy of the mobile ion

Screened cation-cation or anion-anion repulsion

energy

Euler's number

Numerical factors

Current

Peukert exponent

Boltzmann constant

Median particle size

Probability that a triggering ion has reached the site within the period $1 / C$

Charges of ions A and B, respectively

Absolute specific capacity at a given C-rate

Relative specific capacity at a given C-rate

Theoretical specific capacity

Covalent radii of atoms $\mathrm{A}$ and $\mathrm{B}$, respectively

Bond distance between cation $\mathrm{A}$ and anion $\mathrm{X}$

Bond distance between cation $\mathrm{A}$ and anion $\mathrm{X}$ that corresponds to a bond valence of $s_{\mathrm{A}-\mathrm{X}}=1$ valence unit.

Bond valence of the interaction between cation $\mathrm{A}$ and anion $\mathrm{X}$

Temperature

Bond valence sum mismatch

Characteristic relaxation frequency of stretched exponential curve, i.e. characteristic $\mathrm{C}$ rate where the capacity drops to $1 / e$ of its value at (infinitely) low discharge rate.

$W_{\text {act }} \quad$ Characteristic relaxation frequency of charge transfer process at the electrode surface

$w \quad$ Characteristic relaxation time $=1 / \mathrm{W}$

$\alpha \quad$ Fraction of theoretical capacity that practically remains inaccessible at low $\mathrm{C}$ rates

$\beta \quad$ Stretching exponent

$\beta_{\text {act }} \quad$ Stretching exponent related to the charge transfer process at the electrode surface

$\gamma \quad$ Pathway dimensionality-dependent pathway tortuosity exponent

\section{Acknowledgements}

This research was supported by the National Research Foundation, Prime Minister's Office, Singapore under its Competitive
Research Programme (CRP Awards NRF-CRP 10-2012-6 and NRF-CRP 8-2011-4). Scholarships to L. L. Wong (jointly funded by NUS and Johnson Matthey PLC) as well as to H. M. Chen (funded by the National Research Foundation, Prime Minister's Office, Singapore) are gratefully acknowledged.

\section{References}

1 A. A. Yaroshevsky, Geochem. Int., 2005, 44, 48-55.

2 R. Berthelot, D. Carlier and C. Delmas, Nat. Mater., 2011, 10, 74-80.

3 B. Xu, D. Qian, Z. Wang and Y. S. Meng, Mater. Sci. Eng., R, 2012, 73, 51-65.

4 M. M. Kalantarian, S. Asgari and P. Mustarelli, J. Mater. Chem. A, 2014, 2, 107-115.

5 W. Peukert, Elektrotech. Z., 1897, 20, 287-288.

6 D. Doerffel and S. Abu Sharkh, J. Power Sources, 2006, 155, 395-400.

7 A. Hausmann and C. Depcik, J. Power Sources, 2013, 235, 148-158.

8 W. Dieterich and P. Maass, Chem. Phys., 2002, 284, 439-467.

9 J. Y. Fu, Philos. Mag., 2014, 94, 1788-1815.

10 S. Adams and R. Prasada Rao, Understanding Ionic Conduction and Energy Storage Materials with Bond-ValenceBased Methods, in Bond Valences, Structure and Bonding, ed. I. D. Brown and K. R. Poeppelmeier, Springer Berlin Heidelberg, 2014, vol. 158, pp. 129-159, DOI: 10.1007/ 430_2013_137.

11 S. Adams, J. Solid State Electrochem., 2010, 14, 1787-1792.

12 S. Adams and R. Prasada Rao, J. Mater. Chem., 2012, 22, 7687-7691.

13 S. Adams and R. Prasada Rao, J. Mater. Chem., 2012, 22, 1426-1434.

14 S. Adams and R. Prasada Rao, Phys. Chem. Chem. Phys., 2009, 11, 3210-3216.

15 S. Adams, Practical Considerations in Determining Bond Valence Parameters, in Bond Valences, Structure and Bonding, ed. I. D. Brown and K. R. Poeppelmeier, Springer Berlin Heidelberg, 2014, vol. 158, pp. 91-128, DOI: $10.1007 /$ 430_2013_96.

16 S. Adams and R. Prasada Rao, Solid State Ionics, 2011, 184, 57-61.

17 M. J. S. Dewar, E. F. Healy and J. J. P. Stewart, J. Chem. Soc., Faraday Trans. 2, 1984, 80, 227-233.

18 S. Adams and R. Prasada Rao, Phys. Status Solidi A, 2011, 208, 1746-1753.

19 J. D. Gale, J. Chem. Soc., Faraday Trans., 1997, 93, 629-637.

20 Materials Studio 6.0, Accelrys Inc., San Diego, CA 92121-3752, 2012.

21 L. L. Wong, H. Chen and S. Adams, Phys. Chem. Chem. Phys, 2015, 17, 9186-9193.

22 P. Barpanda, G. Oyama, S. Nishimura, S. C. Chung and A. Yamada, Nat. Commun., 2014, 5, 4358.

23 J. Kim, I. Park, H. Kim, K.-Y. Park, Y.-U. Park and K. Kang, Adv. Energy Mater., 2016, 6, 1502147. 
24 P. Singh, K. Shiva, H. Celio and J. B. Goodenough, Energy Environ. Sci., 2015, 8, 3000-3005.

25 Y. Meng, T. Yu, S. Zhang and C. Deng, J. Mater. Chem. A, 2016, 4, 1624-1631.

26 G. Li, D. Jiang, H. Wang, X. Lan, H. Zhong and Y. Jiang, J. Power Sources, 2014, 265, 325-334.

27 C.-Y. Chen, K. Matsumoto, T. Nohira and R. Hagiwara, J. Electrochem. Soc., 2015, 162, A176-A180.

28 G. Longoni, J. E. Wang, Y. H. Jung, D. K. Kim, C. M. Mari and R. Ruffo, J. Power Sources, 2016, 302, 61-69.

29 H. Kim, G. Yoon, I. Park, K.-Y. Park, B. Lee, J. Kim, Y.-U. Park, S.-K. Jung, H.-D. Lim, D. Ahn, S. Lee and K. Kang, Energy Environ. Sci., 2015, 8, 3325-3335.

30 H. Kim, I. Park, D.-H. Seo, S. Lee, S.-W. Kim, W. J. Kwon, Y.-U. Park, C. S. Kim, S. Jeon and K. Kang, J. Am. Chem. Soc., 2012, 134, 10369-10372.

31 H. Kim, I. Park, S. Lee, H. Kim, K.-Y. Park, Y. Park, H. Kim, J. Kim, H.-D. Lim, W.-S. Yoon and K. Kang, Chem. Mater., 2013, 25, 3614-3622.

32 S. Zhang, C. Deng and Y. Meng, J. Mater. Chem. A, 2014, 2, 20538-20544.

33 P. Barpanda, G. Liu, M. Avdeev and A. Yamada, ChemElectroChem, 2014, 1, 1488-1491.

34 Y. Kee, N. Dimov, A. Staikov, P. Barpanda, Y.-C. Lu, K. Minami and S. Okada, RSC Adv., 2015, 5, 64991-64996.

35 C. S. Park, H. Kim, R. A. Shakoor, E. Yang, S. Y. Lim, R. Kahraman, Y. Jung and J. W. Choi, J. Am. Chem. Soc., 2013, 135, 2787-2792.

36 H. Kim, C. S. Park, J. W. Choi and Y. Jung, Angew. Chem., Int. Ed., 2016, 55, 6662-6666.

37 P. P. Prosini, C. Cento, A. Masci and M. Carewska, Solid State Ionics, 2014, 263, 1-8.

38 Y. Zhu, Y. Xu, Y. Liu, C. Luo and C. Wang, Nanoscale, 2013, 5, 780-787.

39 Y.-L. Ruan, K. Wang, S.-D. Song, X. Han and B.-W. Cheng, Electrochim. Acta, 2015, 160, 330-336.

40 Y.-U. Park, D.-H. Seo, H.-S. Kwon, B. Kim, J. Kim, H. Kim, I. Kim, H.-I. Yoo and K. Kang, J. Am. Chem. Soc., 2013, 135, 13870-13878.

41 L. Wang, J. Song, R. Qiao, L. A. Wray, M. A. Hossain, Y.D. Chuang, W. Yang, Y. Lu, D. Evans, J.-J. Lee, S. Vail, X. Zhao, M. Nishijima, S. Kakimoto and J. B. Goodenough, J. Am. Chem. Soc., 2015, 137, 2658-2664.

42 H. Chen, Q. Hao, O. Zivkovic, G. Hautier, L.-S. Du, Y. Tang, Y.-Y. Hu, X. Ma, C. P. Grey and G. Ceder, Chem. Mater., 2013, 25, 2777-2786.

43 S. Xu, Y. Wang, L. Ben, Y. Lyu, N. Song, Z. Yang, Y. Li, L. Mu, H.-T. Yang, L. Gu, Y.-S. Hu, H. Li, Z.-H. Cheng, L. Chen and X. Huang, Adv. Energy Mater., 2015, 5, 1501156.

44 M. Jayakumar, K. Hemalatha, K. Ramesha and A. S. Prakash, Phys. Chem. Chem. Phys., 2015, 17, 20733-20740.

45 Y. Kawabe, N. Yabuuchi, M. Kajiyama, N. Fukuhara, T. Inamasu, R. Okuyama, I. Nakai and S. Komaba, Electrochem. Commun., 2011, 13, 1225-1228.

46 M. Xu, L. Wang, X. Zhao, J. Song, H. Xie, Y. Lua and J. B. Goodenough, Phys. Chem. Chem. Phys., 2013, 15, 13032-13037.
47 K. H. Ha, S. H. Woo, D. Mok, N.-S. Choi, Y. Park, S. M. Oh, Y. Kim, J. Kim, J. Lee, L. F. Nazar and K. T. Lee, Adv. Energy Mater., 2013, 3, 770-776.

48 R. Kohlrausch, Ann. Phys., 1854, 167, 56-82; R. Kohlrausch, Ann. Phys., 1854, 167, 179-214.

49 G. Williams and D. C. Watts, Trans. Faraday Soc., 1970, 66, 80-85.

50 S. H. Glarum, J. Chem. Phys., 1960, 33, 369.

51 P. Bordewijk, Chem. Phys. Lett., 1975, 32, 592.

52 S. R. Elliott and A. P. Owens, Philos. Mag. B, 1989, 60, 777-792.

53 J. Klafter and M. F. Shlesinger, Proc. Natl. Acad. Sci. U. S. A., 1986, 83, 848.

54 K. L. Ngai, Comments Solid State Phys., 1979, 9, 127; K. L. Ngai, Comments Solid State Phys., 1979, 9, 141; K. L. Ngai and R. W. Rendell, J. Non-Cryst. Solids, 1990, 131, 233.

55 (a) K. Funke, B. Roling and M. Lange, Solid State Ionics, 1998, 105, 195-208; (b) K. Funke, R. D. Banhatti and C. Cramer, Phys. Chem. Chem. Phys., 2005, 7, 157-165.

56 S. Guo, H. Yu, D. Liu, W. Tian, X. Liu, N. Hanada, M. Ishida and H. Zhou, Chem. Commun., 2014, 50, 7998-8001.

57 X. Jiang, S. Liu, H. Xu, L. Chen, J. Yang and Y. Qian, Chem. Commun., 2015, 51, 8480-8483.

58 G. Oyama, S.-i. Nishimura, Y. Suzuki, M. Okubo and A. Yamada, ChemElectroChem, 2015, 2, 1019-1023.

59 T. Shiratsuchi, S. Okada, J. Yamaki and T. Nishida, J. Power Sources, 2006, 159, 268-271.

60 T. Balic Zunic, A. Garavelli, P. Acquafredda, E. Leonardsen and S. P. Jakobsson, Mineral. Mag., 2009, 73, 51-57.

61 T. Honma, T. Togashi, N. Ito and T. Komatsu, J. Ceram. Soc. Jpn., 2012, 120, 344-346.

62 H. Kim, R. A. Shakoor, C. Park, S. Y. Lim, J. S. Kim, Y. N. Jo, W. Cho, K. Miyasaka, R. Kahraman, Y. Jung and J. W. Choi, Adv. Funct. Mater., 2013, 23, 1147-1155.

63 P. Barpanda, G. Liu, C. D. Ling, M. Tamaru, M. Avdeev, S. Chung, Y. Yamada and A. Yamada, Chem. Mater., 2013, 25, 3480-3487.

64 J. M. Clark, P. Barpanda, A. Yamada and M. Islam, J. Mater. Chem. A, 2014, 2, 11807-11812.

65 P. Barpanda, T. Ye, S. Nishimura, S. Chung, Y. Yamada, M. Okubo, H. Zhou and A. Yamada, Electrochem. Commun., 2012, 24, 116-119.

66 J. Angenault, J. C. Couturier, M. Quarton and F. Robert, Eur. J. Solid State Inorg. Chem., 1995, 32, 335-343.

67 S. M. Wood, C. Eames, E. Kendrick and M. S. Islam, J. Phys. Chem. C, 2015, 119, 15935-15941.

68 D. Kundu, R. Tripathi, G. Popov, W. R. M. Makahnouk and L. F. Nazar, Chem. Mater., 2015, 27, 885-891.

69 C. Wang, M. Sawicki, J. A. Kaduk and L. L. Shaw, J. Electrochem. Soc., 2015, 162, A1601-A1609.

70 S. Adams, Appl. Energy, 2012, 90, 323-328.

71 R. P. Rao, M. V. Reddy, S. Adams and B. V. R. Chowdari, Mater. Res. Bull., 2015, 66, 71-75.

72 V. Palomares, M. Casas-Cabanas, E. Castillo-Martínez, M. H. Han and T. Rojo, Energy Environ. Sci., 2013, 6, 2312-2337. 
73 R. Prasada Rao, M. H. Chen and S. Adams, J. Solid State Electrochem., 2012, 16, 3349-3354.

74 Z. Jian, C. Yuan, W. Han, X. Lu, L. Gu, X. Xi, Y.-S. Hu, H. Li, W. Chen, D. Chen, Y. Ikuhara and L. Chen, Adv. Funct. Mater., 2014, 24, 4265-4272.

75 S. Y. Lim, H. Kim, R. A. Shakoor, Y. Jung and J. W. Choi, J. Electrochem. Soc., 2012, 159, A1393-A1397.

76 Z. Jian, Y. Sun and X. Ji, Chem. Commun., 2015, 51, 6381-6383.

77 Z. L. Jian, L. Zhao, H. L. Pan, Y. S. Hu, H. Li, W. Chen and L. Q. Chen, Electrochem. Commun., 2012, 14, 86-89.

78 K. M. Bui, V. A. Dinh, S. Okada and T. Ohno, Phys. Chem. Chem. Phys., 2015, 17, 30433-30439.

79 J. P. Boilot, G. Collin and Ph. Colomban, Mater. Res. Bull., 1987, 22, 669-676.

80 J. Gopalakrishnan and K. K. Rangan, Chem. Mater., 1992, 4, 745-747.

81 W. Song, X. Cao, Z. Wu, J. Chen, K. Huangfu, X. Wang, Y. Huang and X. Ji, Phys. Chem. Chem. Phys., 2014, 16, 17681-17687.

82 H. Li, X. Yu, Y. Bai, F. Wu, C. Wu, L. Y. Liu and X.-Q. Yang, J. Mater. Chem. A, 2015, 3, 9578-9586.
83 A. D. Robertson, A. R. West and A. G. Ritchie, Solid State Ionics, 1997, 104, 1-11.

84 R. A. Shakoor, D. H. Seo, H. Kim, Y. U. Park, J. Kim, S. W. Kim, H. Gwon, S. Lee and K. Kang, J. Mater. Chem., 2012, 22, 20535-20541.

85 M. Bianchini, N. Brisset, F. Fauth, F. Weill, E. Elkaim, E. Suard, C. Masquelier and L. Croguennec, Chem. Mater., 2014, 26, 4238-4247.

86 I. L. Matts, S. Dacek, T. K. Pietrzak, R. Malik and G. Ceder, Chem. Mater., 2015, 27, 6008-6015.

87 W. Song, X. Cao, Z. Wu, J. Chen, Y. Zhu, H. Hou, Q. Lan and X. Ji, Langmuir, 2014, 30, 12438-12446.

88 Y. Qi, L. Mu, J. Zhao, Y.-S. Hu, H. Liu and S. Dai, Angew. Chem., Int. Ed., 2015, 54, 9911-9916.

89 H. Jin, J. Dong, E. Uchaker, Q. Zhang, X. Zhou, S. Hou, J. Li and G. Cao, J. Mater. Chem. A, 2015, 3, 17563-17568.

90 M. Xu, P. Xiao, S. Stauffer, J. Song, G. Henkelman and J. B. Goodenough, Chem. Mater., 2014, 26, 3089-3097.

91 P. Serras, V. Palomares, P. Kubiak, L. Lezama and T. Rojo, Electrochem. Commun., 2013, 34, 344-347.

92 R. Malik, D. Burch, M. Bazant and G. Ceder, Nano Lett., 2010, 10, 4123-4127. 